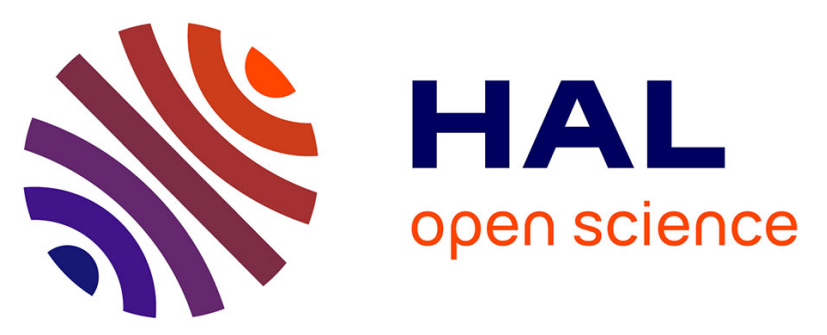

\title{
Glycogen synthase kinase 3-mediated voltage-dependent anion channel phosphorylation controls outer mitochondrial membrane permeability during lipid accumulation.
}

Cecile Martel, Maya Allouche, Davide Degli Esposti, Elena Fanelli, Céline Boursier, Céline Henry, Joel Chopineau, Giuseppe Calamita, Guido Kroemer, Antoinette Lemoine, et al.

\section{- To cite this version:}

Cecile Martel, Maya Allouche, Davide Degli Esposti, Elena Fanelli, Céline Boursier, et al.. Glycogen synthase kinase 3-mediated voltage-dependent anion channel phosphorylation controls outer mitochondrial membrane permeability during lipid accumulation.. Hepatology, 2013, 57 (1), pp.93-102. 10.1002/hep.25967 . hal-00734262

\author{
HAL Id: hal-00734262 \\ https://hal.science/hal-00734262
}

Submitted on 21 Sep 2012

HAL is a multi-disciplinary open access archive for the deposit and dissemination of scientific research documents, whether they are published or not. The documents may come from teaching and research institutions in France or abroad, or from public or private research centers.
L'archive ouverte pluridisciplinaire HAL, est destinée au dépôt et à la diffusion de documents scientifiques de niveau recherche, publiés ou non, émanant des établissements d'enseignement et de recherche français ou étrangers, des laboratoires publics ou privés. 


\author{
GSK3-mediated VDAC phosphorylation controls outer mitochondrial membrane \\ permeability during lipid accumulation \\ entsing \\ - \\ Cecile MARTEL ${ }^{1,2}$, Maya ALLOUCHE ${ }^{3}$, Davide DEGLI ESPOSTI ${ }^{2}$, Elena FANELLI ${ }^{4}$, Céline \\ BOURSIER $^{5}$, Céline HENRY ${ }^{6}$, Joel CHOPINEAU ${ }^{3,7}$, Giuseppe CALAMITA ${ }^{4}$, Guido KROEMER $^{8-12}$, \\ Antoinette LEMOINE ${ }^{2 *}$, Catherine BRENNER ${ }^{1^{*}}$

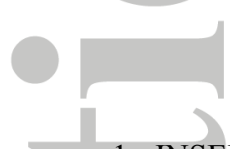 \\ 1. INSERM U769, LabEx LERMIT, Université Paris-Sud, Faculté de Pharmacie, 5 Rue J.-B. Clément, \\ Châtenay-Malabry Cedex, France, \\ 2. INSERM U1004, Université de Paris-Sud, PRES UniverSud Paris, Hôpital Paul Brousse, 14, avenue Paul \\ Vaillant Couturier, Villejuif, France, \\ 3. Institut Charles Gerhardt, UMR 5253 CNRS, Equipe MACS, UFR des Sciences Pharmaceutiques et \\ Biologiques. 15, avenue Charles Flahault - BP 14 491, Montpellier, France, \\ 4. Dipartimento di Fisiologia Generale ed Ambientale, Università degli Studi di Bari, Aldo Moro, Bari, Italy, \\ 5. INSERM IFR 141, Université Paris-Sud, Faculté de Pharmacie, 5 Rue J.-B. Clément, Châtenay-Malabry \\ Cedex, France, \\ 6. INRA, UMR 1319 Micalis, PAPPSO, Jouy-en-Josas, France, \\ 7. Université de Nîmes, Nîmes, France, \\ 8. INSERM, U848, 39 rue Calmette Desmoulins, Villejuif, France, \\ 9. Metabolomics Platform, Institut Gustave Roussy, Pavillon de Recherche 1, Villejuif, France, \\ 10. Centre de Recherche des Cordeliers, 15 rue de l'Ecole de Médecine, Paris, France, \\ 11. Pôle de Biologie, Hôpital Européen Georges Pompidou, AP-HP, 20 rue Leblanc, Paris, France, \\ 12. Université Paris Descartes, Faculté de Médecine, 15 rue de l'Ecole de Médecine, Paris, France. \\ * : share senior co-authorship
}

Short title: VDAC phosphorylation

Keywords: mitochondria, VDAC, GSK3, lipotoxicity, steatosi

Address correspondence: Dr Catherine Brenner, INSERM U769, LabEx LERMIT, Université Paris-Sud, 5 Rue J.-B. Clément, 92290 Châtenay-Malabry Cedex, France. Tel. 33-1 46835757 - Fax. 33-1 46835475 - Email. catherine.brenner-jan@u-psud.fr

\title{
Abbreviations:
}

AIF, apoptosis inducing factor; ANT, adenine nucleotide translocase; $\mathrm{Ca}^{2+}$, calcium; CsA, cyclosporine A; Cyt c, cytochrome $c$; DIDS, disodium 4,4'-diisothiocyanatostilbene-2,2'-disulfonate; $\Delta \Psi \mathrm{m}$, mitochondrial inner membrane potential; FA, fatty acids; GSK3, glycogen synthase kinase 3; HFD, high fat diet; MC, mitochondrial complex; MMP, mitochondrial membrane permeabilization; NAFLD, non-alcoholic fatty liver disease; ND, nondiet; OM, outer membrane; PI3K, Phosphoinositide 3 kinase; PT, permeability transition; PTP, permeability transition pore; P-Thr, phosphorylated threonine, P-VDAC, phosphorylated voltage-dependent anion channel; ROS, reactive oxygen species; $\mathrm{SD}$, standard deviation; thr, threonine; TNF, tumor necrosis factor; VDAC, voltage-dependent anion channel; Wort, Wortmannin.

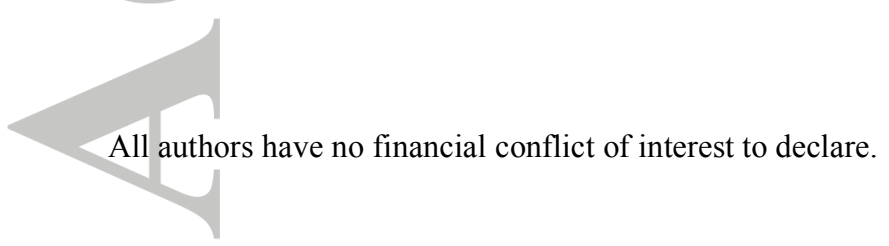

This article has been accepted for publication and undergone full peer review but has not been through the copyediting, typesetting, pagination and proofreading process which may lead to differences between this version and the Version of Record. Please cite this article as an 'Accepted Article', doi: 10.1002/hep.25967 


\section{ABSTRACT}

Non-alcoholic steatosis is a liver pathology characterized by fat accumulation and severe metabolic alterations involving early mitochondrial impairment and late hepatocyte cell death. However, mitochondrial dysfunction mechanisms remain elusive. Using four models of nonalcoholic steatosis, i.e. livers from patients with fatty liver disease, $o b / o b$ mice, mice fed a high fat diet and in vitro models of lipotoxicity, we show that outer mitochondrial membrane permeability is altered and identified a post-translational modification of VDAC, a membrane channel and NADH oxidase, as a cause of early mitochondrial dysfunction. Thus, in nonalcoholic steatosis, VDAC exhibits reduced threonine phosphorylation, which increases the influx of water and calcium into mitochondria, sensitizes the organelle to matrix swelling, depolarization and cytochrome $c$ release without inducing cell death. This also amplifies VDAC enzymatic and channel activities regulation by calcium and modifies its interaction with proteic partners. Moreover, lipid accumulation triggers a rapid lack of VDAC phosphorylation by GSK3. Pharmacological and genetic manipulations proved GSK3 to be responsible for VDAC phosphorylation in normal cells. Notably, VDAC phosphorylation level correlated with steatosis severity in patients. In conclusion, VDAC acts as an early sensor of lipid toxicity and its GSK3-mediated phosphorylation status controls outer mitochondrial membrane permeabilization in hepatosteatosis.

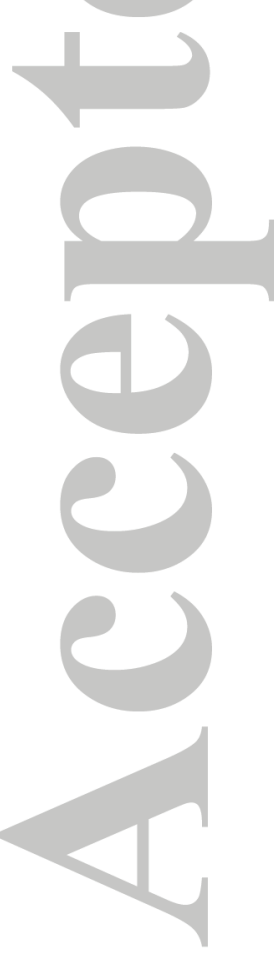




\section{INTRODUCTION}

Non-alcoholic fatty liver disease (NAFLD) is accompanied by hepatosteatosis, a clinical condition characterized by excessive accumulation of lipids within hepatocytes and complex metabolic alterations ${ }^{1,2}$. Although reversible in early stages, steatosis can lead to more aggressive forms of liver injury such as hepatitis, cirrhosis and hepatocarcinoma ${ }^{3}$. Investigation of patients with hepatosteatosis showed that mitochondria harbor prominent morphologic and functional abnormalities, suggesting a central role of these organelles in the pathogenesis ${ }^{4}$. Mitochondria can influence cell fate at the levels of energy production, lipid metabolism, production and detoxification of reactive oxygen species (ROS) and release of pro-apoptotic proteins ${ }^{5}$. All these alterations favor an increase in apoptotic and necrotic hepatocyte cell death.

The voltage-dependent anion channel (VDAC) or porin is the most abundant protein expressed in the mitochondrial outer membrane (OM). In physiological conditions, VDAC allows the flux of ions and metabolites necessary to mitochondrial metabolism and cell growth $^{6,7}$. Thus, VDAC channel closure by tubulin limits mitochondrial metabolism, thereby decreasing the mitochondrial inner membrane potential $(\Delta \Psi \mathrm{m})^{8}$. VDAC is also implicated in NADH oxidation and then, plays a role in cellular redox metabolism ${ }^{9}$. In conditions of lethal stress, VDAC can contribute to the pro-apoptotic mitochondrial membrane permeabilization (MMP) (for review ${ }^{5}$ ), either via homo-oligomerization, direct physical interactions with endogenous members of the Bcl-2 family (e.g. Bax), adenine nucleotide translocase (ANT) and virus-encoded Bcl-2-like proteins or via its impact on calcium $\left(\mathrm{Ca}^{2+}\right)$ fluxes and $\mathrm{ROS}$ detoxification. Nonetheless, the exact role of VDAC in MMP and permeability transition (PT) is debated and the molecular mechanisms that determine VDAC transition from a normal to a lethal function are elusive. 
Here, we provide evidence that, in steatotic hepatocytes, the lack of VDAC phosphorylation sensitizes hepatocytes to $\mathrm{Ca}^{2+}$-induced MMP. Using cellular and molecular approaches, we demonstrate that VDAC lack of phosphorylation is accompanied by the decrease of interaction with the serine/threonine glycogen synthase kinase 3 (GSK3) and Bcl- $\mathrm{X}_{\mathrm{L}}$ in mitochondria and enhances the stimulation of VDAC functions by $\mathrm{Ca}^{2+}$.

\section{MATERIALS AND METHODS}

\section{Animal models}

Female 6-12 weeks old lean (C57BL/6J) and ob/ob (B6.V-Lepob/J) mice were purchased from Janvier (Le Genest Saint Isle, France). Male 4-week-old C57BL/6J mice (Harlan, Udine, Italy) were acclimatized to laboratory conditions for one week before being randomly assigned to either the high fat or standard chow diet (Altromin-Rieper, Vandoies, Italy).

\section{Collection of human liver biopsies}

Eight frozen biopsies were chosen among liver biopsies collected during graft harvesting in our institution. The study protocol follows the recommendations of the ethical guidelines of the 1975 Declaration of Helsinki and was approved by our ethical committee.

\section{Cell culture}

HHL-5, immortalized non-cancerous primary hepatocytes (a generous gift from Dr A. Patel, University of Glasgow, UK) ${ }^{10}$ are cultured in DMEM-F12 (Dulbecco's Modified Eagle's Medium) supplemented with $10 \%$ fetal bovine serum, $1 \%$ glutamax and $1 \%$ penicillin/streptomycin, in $5 \% \mathrm{CO}_{2}$ at $37^{\circ} \mathrm{C}$ supplemented with $2 \% \mathrm{BSA}$ and $2 \mathrm{mM}$ oleate/palmitate (2:1 ratio), as described in the literature ${ }^{11}$ and the cells were treated with this medium for 3 to $30 \mathrm{~h}$.

All samples collections and protocols are described in supporting informations. 


\section{RESULTS}

\section{Steatosis promotes alteration of mitochondrial membrane permeability (MMP)}

Mitochondrial modifications were investigated in mice that become obese due to a genetic leptin-deficiency caused by the $o b / o b$ mutation ${ }^{13}$. Transmission electron microscopy revealed the presence of numerous mega-mitochondria with matrix swelling, loss of internal material and $\mathrm{OM}$ ruptures in a population of isolated mitochondria from $o b / o b$ mice (Figure 1A).

These structural alterations correlated with an increase in MMP and of mitochondrial volume. As compared to mitochondria from lean mice, $\mathrm{ob} / \mathrm{ob}$ mitochondria exhibited accelerated $\mathrm{Ca}^{2+}$ induced matrix swelling (Figure 1B) and $\Delta \Psi \mathrm{m}$ dissipation (Figure 1C). Permeabilized fatty acid (FA)-treated human immortalized hepatocytes (HHL-5 cells) ${ }^{10}$ (Supplementary Figure 1) also proved to be more sensitive to $\mathrm{Ca}^{2+}$-triggered $\Delta \Psi \mathrm{m}$ loss than untreated cells (Figure 1D). Moreover, mitochondria from $o b / o b$ mice were more permeable to water, both in normal condition and upon $\mathrm{Ca}^{2+}$ stimulation of PT (Figure 2A). In the presence of cyclosporin A (CsA), the prototypic inhibitor of PT, the permeability of control and $o b / o b$ mitochondria was reduced to similarly low levels (Figure 2A). As a consequence, the pro-apoptotic intermembrane space protein, cytochrome $c$ (Cyt c) was found in the $100.000 \times \mathrm{g}$ supernatants of isolated $o b / o b$ mitochondria from obese mice (Figure 2B). This was not the case for the apoptosis-inducing factor (AIF), another pro-apoptotic protein (Figure 2B). Caspase 3/7 activities were not enhanced by FA accumulation in vitro or in vivo (Figure 2CD), suggesting that the apoptotic signaling cascade was not activated. The distribution of Cyt $c$ in ob/ob and lean mouse livers was also analyzed by immunohistochemistry (Supplementary Figure 2). Cyt $c$ was particularly expressed in portal tracts and in some centrolobular areas, while lobular hepatocytes presented a lesser staining (Supplementary Figure 2A,B). In livers obtained from lean mice, a punctate cytoplasmic staining was 
observed in hepatocytes, while in steatotic or also some non-steatotic hepatocytes from $o b / o b$ mice livers a more diffused cytoplasmic staining was observed. These results confirm that in steatotic livers, more hepatocytes present a cytoplasmic liberation of Cyt $c$ from mitochondria probably due to an increased membrane permeabilization.

\section{Calcium regulates VDAC functions in steatosis}

To assess the causative link between mitochondrial proteins modification and mitochondrial dysfunction, the pharmacological regulation of MMP was examined. Thus, $\mathrm{Ca}^{2+}$ induced the maximal swelling and depolarization in $30 \mathrm{~min}$ and $\mathrm{CsA}$ inhibited $\mathrm{Ca}^{2+}$-induced swelling and depolarization in both mitochondrion types nearly as efficiently as the $\mathrm{Ca}^{2+}$ chelator EGTA (Figure 3A and B). The VDAC blocker disodium 4,4'-diisothiocyanatostilbene-2,2'disulfonate (DIDS) and the permeability transition pore (PTP) inhibitor N-[(3,5-di-tert-butyl4-hydroxy-1-thiophenyl)]-3-propyl-N'-(2,3,4-trimethoxybenzyl) piperazine difumarate (S15176) ${ }^{14,15}$ were less efficient in preventing PT induction in $o b / o b$ mitochondria than in control mitochondria (Figure 3A and B). This points to a role for PTP and VDAC in the differential response to $\mathrm{Ca}^{2+}$. No differential effect of bongrekic acid, an adenine nucleotide translocase (ANT) inhibitor, was observed suggesting that ANT is not involved in the difference of response of both types of mitochondria to $\mathrm{Ca}^{2+}$ (not shown).

Similar levels of VDAC were detected in liver mitochondria extracts from lean and $o b / o b$ mice (Figure 3C). Nonetheless, isolated $o b / o b$ mitochondria accumulated significantly more $\mathrm{Ca}^{2+}$ than control mitochondria (Figure 3D). Moreover, control VDAC proteoliposomes accumulated less $\mathrm{Ca}^{2+}$ than proteoliposomes, which contained VDAC purified from $o b / o b$ mice (Figure 3E, Supplementary Figure 3). Furthermore, the NADH oxidase activity of

VDAC was higher in VDAC purified from $o b / o b$ mice and was enhanced in the presence of 
$\mathrm{Ca}^{2+}$ (Supplementary Table 1). Both $\mathrm{Ca}^{2+}$ accumulation and NADH oxidase activity were inhibited by DIDS (Supplementary Figure 4).

Finally, we determined VDAC channel conductance following reconstitution of the pure native protein into planar lipid bilayer. In the absence of $\mathrm{Ca}^{2+}$, VDAC from lean mice exhibited classical hallmarks, i.e. alternation of open (o) and closed (c) states at low potentials with a symetrical behaviour (Figure 4A). At $\pm 20 \mathrm{mV}$, the main difference was that VDAC purified from $o b / o b$ mice liver opened permanently (Figure 4, Supplementary Table 2). Moreover, in the presence of $0.5 \mathrm{mM} \mathrm{Ca}^{2+}$, VDAC from lean mice liver behavior remains symetrical, the amplitude level of the open states and the opening duration increased significantly. In contrast, VDAC from $o b / o b$ mice liver behaved asymmetrically in response to positive and negative potentials. Thus, at $-20 \mathrm{mV}$, the channel permanently closed (Figure 4, Supplementary Table 2). This suggests a remarkable change in the gating properties of the channel.

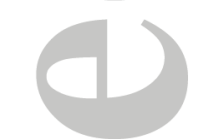

\section{VDAC phosphorylation status in steatotic patients and experimental models}

In mammals, VDAC is expressed as three homologous isoforms, VDAC1 to VDAC3 which possess multiple threonine (Thr) residues (Supplementary Figure 5) ${ }^{16}$. First, we analyzed the level of Thr phosphorylation of purified VDAC from liver of lean and $o b / o b$ mice by immunoblotting with an antibody specific for phosphorylated Thr (P-Thr) and found a unique $34 \mathrm{kDa}$ band co-migrating with VDAC (Figure 5A), consistent with a phosphorylation of VDAC on one or several Thr residues in lean mice and a lack of phosphorylation in $o b / o b$ mice. Second, we analyzed total extracts of human liver biopsies with variable grades of hepatosteatosis and mitochondrial extracts from mice fed a high fat diet (HFD) confirming the difference of P-Thr phosphorylation between steatotic and lean samples (Figure 5B-C, Supplementary Table 3). Moreover, VDAC phosphorylation status correlated with the 
severity of the liver pathology (Figure 5B). Third, we investigated the lack of phosphorylation induced by FA treatment in HHL-5 cells and found that the loss of P-Thr phosphorylation is significant from $6 \mathrm{hr}$ to $30 \mathrm{hr}$ of FA treatment (Figure 5D). To demonstrate the identity of VDAC as the $34 \mathrm{kDa}$ band identified by P-Thr immunoblotting, two-dimensional polyacrylamide gel electrophoresis (2D-PAGE) followed by immunoblotting was performed. This led to the identification of eight spots reacting with VDAC-specific antibodies and some of them, with the antibody for P-Thr (Figure 5E-F). The identity of VDAC 1 to 3 in these double-labelled spots was confirmed by nanoliquid chromatography and mass spectrometry (Supplementary Table 4). Thus, in normal conditions, VDAC is phosphorylated on one or several Thr residues. This phosphorylation is significantly reduced in steatotic samples from patients, in fat accumulating HHL-5 cells, as well as in obese mice. These results reveal the existence of a lipid-induced signaling pathway leading to the lack of phosphorylation of VDAC.

\section{VDAC interactome changes in steatosis}

Next, blue native polyacrylamide gel electrophoresis (BN-PAGE) revealed the existence of numerous multiprotein complexes (MC) containing VDAC (Figure 6A-B). Surprisingly, a complex of $175 \mathrm{kDa}\left(\mathrm{MC}_{175 \mathrm{kDa}}\right)$, present in control mitochondria, was totally absent in $o b / o b$ mitochondria (Figure 6B). $\mathrm{MC}_{175 \mathrm{kDa}}$ contains P-VDAC, the serine/threonine kinase GSK3, the anti-apoptoptic protein-Bcl-X (Figure 6C). Glucokinase, ANT, Akt, P-Akt, Bax, Bak and cyclophilin $\mathrm{D}$, which are putative partners of VDAC ${ }^{17}$ were not present in $\mathrm{MC}_{175 \mathrm{kDa}}$ (not shown). Moreover, we observed that GSK3 was similarly associated with both type of mitochondria and mainly in the cytoplasm, whereas the amount of P-GSK3 $\beta$ increased in $o b / o b$ mitochondria as well as in cytoplasm. Bcl- $\mathrm{X}_{\mathrm{L}}$ was found in the complex in lean mitochondria while in $o b / o b$ mice, was more abundant into the cytosol, suggesting a 
regulatory flux out of the mitochondria (Figure 6D). Thus, $\mathrm{MC}_{175 \mathrm{kDa}}$ might contribute to the relative stability of non-steatotic mitochondrial membranes (Figure 6E).

\section{GSK3 phosphorylates VDAC}

Prompted by the fact that GSK3 can phosphorylate VDAC, we assessed the proportion of inactive, phosphorylated GSK3 among total GSK3 protein (P-GSK3/GSK3 ratio) in mitochondrial fraction by immunoblotting. In isolated functional mitochondria from lean and ob/ob livers, P-Thr phosphorylation of VDAC was inversely related to that of GSK3 (Figure 7A). Moreover, upon addition of FA to HHL-5 cells, P-Thr of VDAC decreased ( 0.46 fold \pm 0.1$)$ and P-GSK3 increased (1.45 fold \pm 0.2$)$ (Figure 7B) as the sensitivity of mitochondria to $\mathrm{Ca}^{2+}$ stimuli increased (Figure 7C). These effects on VDAC phosphorylation (Figure 7B) and inner membrane depolarization (Figure 7C) could be reversed by exposure to wortmannin (Wort), a phosphoinositide 3-kinase (PI3K) inhibitor that stimulates GSK3 kinase activity and decreases GSK3 phosphorylation ${ }^{18}$. Indeed, Wort rescues partially VDAC phosphorylation $(0.74$ fold \pm 0.07$)$ from FA treatment (Figure 7B). In the absence of FA, SB216763, a specific GSK3 inhibitor ${ }^{19}$, decreased P-Thr of VDAC $(0.65$ fold \pm 0.1$)$ (Figure 7B) and increased the sensitivity to $\mathrm{Ca}^{2+}$ (Figure 7C), mimicking FA accumulation and steatotic condition. To demonstrate that GSK3 is the kinase or, at least, one of the kinases that contribute to VDAC phosphorylation in lean condition, we reduced its expression of $80 \%$ by siRNA and observed a 46\% decreased in P-Thr VDAC in HHL-5 cells (Figure 7D). Finally, using recombinant (i.e. VDAC1, GSK3, Bcl-X $\mathrm{L}_{\mathrm{L}}$ ) and native purified proteins (i.e. VDAC), we observed that in vitro $\mathrm{VDAC}$ and $\mathrm{Bcl}-\mathrm{X}_{\mathrm{L}}$ can be direct substrates for phosphorylation by GSK3 $\beta$ and suggests that no other kinase is needed (Supplementary Figure 5).

\section{DISCUSSION}


Unraveling the initial molecular mechanisms leading to fatty liver disease in humans is of major clinical importance. Since activation of signaling pathways may precede the clinical symptoms ${ }^{1}$, a series of models of liver steatosis were used to study the early stage of

NAFLD. This led us to show, for the first time, that liver steatosis in humans is associated with a lack of VDAC phosphorylation. This modification was also observed both in a genetic model of obesity, the $o b / o b$ mice, which is devoid of inflammation and fibrosis, at least in young animals ${ }^{13}$ and in the steatotic liver of HFD-fed mice. No change in other phosphorylable amino acids, such as tyrosine or serine was observed (not shown). These observations suggest that VDAC lack of phosphorylation may represent a hallmark of steatosis in mammals.

In addition to their impaired metabolic function ${ }^{4}$, we show for the first time that mitochondria from $\mathrm{ob} / \mathrm{ob}$ mice are more prone to $\mathrm{Ca}^{2+}$-induced PT, water and small molecules entry, and Cyt $c$ release, suggesting a sensitization of the mitochondrial pathway of apoptosis. Indeed, tumor necrosis factor (TNF)-induced apoptosis and $\mathrm{Ca}^{2+}$ release by endoplasmic reticulum have been shown to be responsible of the massive hepatocyte loss observed in late stages of NAFLD ${ }^{20,21}$. The absence of apoptosis and caspase activation in $o b / o b$ mice might be explained by the earliness of the model ${ }^{22}$. The cellular experiments revealed that intracellular FA accumulation is rapidly followed by VDAC dephosphorylation and $\Delta \Psi \mathrm{m}$ loss sensitization. Thus, our current data obtained in $o b / o b$ mice and FA-treated cells offer novel insights into the early phases of NAFLD pathogenesis and early mitochondrial alterations. Importantly, we found differences in VDAC functions that were exacerbated by $\mathrm{Ca}^{2+}$. Thus, the level of VDAC phosphorylation proved to modulate the ionic channel permeability of VDAC in response to $\mathrm{Ca}^{2+}$, which may influence mitochondrial $\mathrm{OM}$ permeability ${ }^{23,24}$. Moreover, the overstimulation of oxidase function of VDAC purified from $o b / o b$ mice by $\mathrm{Ca}^{2+}$ may affect the cellular metabolism by increasing $\mathrm{NAD}^{+}$levels available either for redox 
processes, ADP-ribosylation reactions or sirtuin-mediated deacetylations ${ }^{25}$. Thus, VDAC phosphorylation is a sensor of lipotoxicity controlling the balance between adaptive response to protect cells from lipotoxicity and stress response to favor hepatocyte cell death.

Lipid-induced lack of VDAC phosphorylation results in an increase of its heterooligomerization state and a change in its interactome. In normal mitochondrial membranes, VDAC was found in an hetero-oligomer of $175 \mathrm{kDa}\left(\mathrm{MC}_{175 \mathrm{kDa}}\right)$ that was not detected in the mitochondria of steatotic hepatocytes suggesting that this complex is involved in the stabilization of mitochondrial $\mathrm{OM}$ via an interaction with $\mathrm{Bcl}-\mathrm{X}_{\mathrm{L}}$, which exerts anti-apoptotic function in mitochondrial membrane ${ }^{26} . \mathrm{MC}_{175 \mathrm{kDa}}$ also contains a fraction of GSK3 supporting the hypothesis that mitochondria-associated GSK3 is the kinase involved in the phosphorylation of VDAC in normal conditions, while we can not exclude the association of other kinase or phosphatase. GSK3 activity is inhibited by phosphorylation on serine residues induced by the activation of upstream kinases depending on tissue- and pathological contexts

27. In ob/ob mice, total GSK3 has been found to be less phosphorylated ${ }^{28}$, but our data indicate that the mitochondrial fraction of GSK3 from $o b / o b$ mice is more phosphorylated. Unexpectedly, Bcl-X $\mathrm{X}_{\mathrm{L}}$ and GSK3 were also enriched in the cytoplasm of $o b / o b$ mice. Based on the evidence that $\mathrm{Bcl}-\mathrm{X}_{\mathrm{L}}$ could be a direct target for GSK3 in vitro, it is tempting to speculate for a role of GSK3 phosphorylation of Bcl- $\mathrm{X}_{\mathrm{L}}$ in steatosis. All the pharmacological or genetic manipulations designed to target directly or indirectly GSK3 converged to propose that VDAC is phosphorylated on a Thr residue by, at least, this kinase. This is reminiscent of previous studies in ischemia/reperfusion of cardiomyocytes ${ }^{29}$ or cancer cells ${ }^{30}$ showing the modification of VDAC phosphorylation by GSK3 on Thr51, that would block VDAC interaction with hexokinase and favor tubulin interaction in vitro ${ }^{31}$. Therefore, our functional data are clearly consistent with a tissue specific role for GSK3 in protecting hepatocytes against lipotoxicity in steatosis. Moreover, GSK3 is a pleitropic kinase involved in 
metabolism via its glycogen synthase activity regulation, in insulin signaling pathway ${ }^{32}$ and in insulin resistance mechanisms ${ }^{33}$. Irrespective of the molecular mechanisms linking FA accumulation and GSK3 phosphorylation, mitochondria-associated GSK3 may link metabolism and MMP via its physical and functional interaction with VDAC.

Based on the hypothesis that VDAC is Thr phosphorylated by GSK3 and the solution structure of VDAC ${ }^{16}$, we speculate that at least some phosphorylated Thr residues are exposed to the cytosol. However, since VDAC is encoded by three distinct isoforms with multiple threonines (from 26 to $31 \mathrm{Thr}$ per isoform), the residues critical for the lipid-related regulation of VDAC remain still elusive.

In conclusion, we identified a novel phosphoregulated mitochondrial complex, $\mathrm{MC}_{175 \mathrm{kDa}}$, that is present in normal mitochondria, yet absent from steatotic mitochondria and involved in mitochondrial $\mathrm{Ca}^{2+}$ and water homeostasis of healthy hepatocytes. Thus, the activation of GSK3 (or the inhibition of the corresponding phosphatase(s)) and/or the pharmacological stabilization of VDAC phosphorylation might constitute a strategy to limit mitochondrial damage and tissue injury in obesity-linked liver pathologies.

\section{FIGURE LEGENDS}

Figure 1. Steatosis and FA accumulation alters mitochondrial morphology, mitochondrial membrane potential and swelling sensitivity to calcium

(A) Representative morphology of isolated liver mitochondria from lean and $o b / o b$ mice by transmission electron microscopy. Scale bar $=1 \mu \mathrm{m}$. (B) Kinetic measurement of matrix swelling (optical density at $540 \mathrm{~nm})(\mathrm{n}=10)$ and $(\mathbf{C})$ transmembrane potential (rhodamine 123 fluorescence arbitrary units) of isolated mitochondria from lean and $o b / o b$ mice livers in response to $25 \mu \mathrm{M} \mathrm{Ca}^{2+}$ addition at $\mathrm{t}_{0}(\mathrm{n}=10)$. (D). Effect of $24 \mathrm{~h}$ of treatment of immortalized 
hepatocytes (HHL-5) with $2 \mathrm{mM}$ fatty acids (FA) on the sensitivity of permeabilized cells to $25 \mu \mathrm{M} \mathrm{Ca}{ }^{2+}$-induced depolarization (rhodamine 123 fluorescence, arbitrary units) $(\mathrm{n}=3)$. Values are mean of triplicates samples \pm SD.

\section{Figure 2. Steatosis alters mitochondrial water permeability, cytochrome $c$ location, but} does not activate caspases $3 / 7$

(A) Mitochondrial membrane water permeability expressed as a rate constant $\left(\mathrm{K}_{\mathrm{i}}, \mathrm{s}^{-1}\right)$ of isolated mitochondria from lean (solid bars) and $o b / o b$ (empty bars) mice livers in response to $\mathrm{Ca}^{2+}$ and CsA (means $\pm \mathrm{SD},{ }^{*} P<0.05$ and $\left.{ }^{* *} P<0.01\right)(\mathrm{n}=4)$. (B) Subcellular localization of Cyt $c$ and AIF determined by fractionation of total liver from lean and $o b / o b$ mice in mitochondria and cytosol and followed by immunoblotting analysis. One representative immunoblot of 3 independent experiments is shown (C, D) Caspases 3/7 activity ratio in HHL-5 cells treated (empty bars) or not (solid bars) with $2 \mathrm{mM} \mathrm{FA}$ and in total liver lysates from lean (solid bars) and ob/ob (empty bars) mice. Caspases activity was measured by a fluorimetric assay $(n=3)$.

\section{Figure 3. Steatosis impacts $\mathrm{Ca}^{2+}$-stimulated channel function of VDAC in $o b / o b$ mice}

(A) Effect of pharmacological inhibitors on $\mathrm{Ca}^{2+}$-induced mitochondrial matrix swelling. Triplicates of mitochondrial proteins are incubated with inhibitors (1 mM EGTA, $5 \mu \mathrm{M}$ CsA, $40 \mu \mathrm{M}$ DIDS, $6 \mu \mathrm{M}$ S15176), then with $25 \mu \mathrm{M} \mathrm{Ca}^{2+}$ and optical density of the suspension was recorded for $30 \mathrm{~min}$. (B) Effect of inhibitors on the transmembrane potential by the measure of the dequenching of Rhod123 fluorescence. ${ }^{*} P<0.05$ vs. lean mice $(\mathrm{n}=5) .(\mathbf{C})$ Expression level of VDAC revealed by SDS-PAGE and immunoblotting. ATPase $\beta$-subunit is used as a loading control $(\mathrm{n}=12)$. (D) $\mathrm{Ca}^{2+}$ accumulation in the matrix of isolated mitochondria determined by the fluorescent probe $\operatorname{Rhod} 2(\mathrm{n}=3)$. (E) $\mathrm{Ca}^{2+}$ accumulation in VDAC 
reconstituted in proteoliposomes determined by the fluorescent probe Fluo4-dextran. VDAC was purified to homogeneity from lean and $o b / o b$ mice liver and reconstituted into liposomes containing Fluo4-dextran. $20 \mu \mathrm{M} \mathrm{Ca}^{2+}$ pulses were added onto liposomes and fluorescence was recorded until equilibration. The solid and empty bars correspond to the lean mice and $o b / o b$ mice, respectively. Results are means $\pm \mathrm{SD},{ }^{*} P<0.05$ vs. lean mice, $\mathrm{n}=3$.

\section{Figure 4. Differential modulation of VDAC single channel by $\mathrm{Ca}^{2+}$}

Single VDAC channels were reconstituted spontaneously into planar lipid bilayers upon addition of purified VDAC from lean (A) and $o b / o b(\mathbf{B})$ mice livers to the cis-compartment containing $1 \mathrm{M} \mathrm{KCl}, 10 \mathrm{mM}$ HEPES $\mathrm{pH} 7.4$ with or without $0.5 \mathrm{mM} \mathrm{Ca}{ }^{2+}$. The resultant channel activity was recorded for at least $2 \mathrm{~min}$ at $\pm 20 \mathrm{mV}$. For analysis, the data were filtered to $1 \mathrm{kHz}$, digitized at $4 \mathrm{kHz}$ and collected on a Pentium computer using Axoxcope10 and a digidata 1440A. Experiments have been repeated 3 times giving similar results. c: closed channel; O : open channel.

\section{Figure 5. Threonine phosphorylation of VDAC is reduced in steatosis}

Phosphorylation of VDAC (P-Thr) in (A) purified VDAC from lean (3 animals) and $o b / o b$ mice (3 animals), (B) total liver of steatotic patients classified in grade 0 (3 patients), grade 1 (2 patients) and grade 2 (3 patients), (C) liver of non-diet mice (ND, 3 animals) and mice fed a high-fat diet (HFD, 6 animals) for 24 weeks, and (D) fatty acids (FA)-induced steatotic cells (results are representative of $n=3$ experiments). Expression and phosphorylation of VDAC were determined by immunoblotting and densitometric analysis (30 $\mu \mathrm{g}$ proteins/lane). Indicated results are means \pm Standard Deviation $(\mathrm{SD})$ with ${ }^{*} P<0.05$ and ${ }^{* *} P<0.01$ vs. lean

or non-diet mice. (E) Identification of VDAC variants by 2D-SDS-PAGE of mitochondrial proteins isolated from lean mice liver and (F) determination of their threonine 
phosphorylation status. One representative gel and one immunoblot of 3 independent experiments are shown. Circles indicate the position of VDAC as revealed by immunoblotting and spectrometric analyses.

\section{Figure 6. Steatosis modulates VDAC interactome}

(A) Mitochondrial proteins from lean mice were separated by 2D BN-PAGE and proteins were stained by silver nitrate. The horizontal insert indicates the position of VDACcontaining complexes and the vertical insert indicates the position of $\mathrm{MC}_{175 \mathrm{kDa}}$. (B) VDAC position in 2D BN-PAGE gels of proteins from lean and $o b / o b$ mice liver was revealed by immunoblotting with an anti-VDAC mAb. A circle indicates the position of a VDAC containing complex, named $\mathrm{MC}_{175 \mathrm{kDa}}$ and shows its absence in obese mice liver. (C) Composition of $\mathrm{MC}_{175 \mathrm{kDa}}$, analyzed by immunoblotting of mitochondrial proteins from lean mice after 2D BN-PAGE. (D) Comparison of GSK3 $\beta$, P-GSK3 $\beta$ and Bcl-X subcellular localisation between lean and $o b / o b$ mice after cellular fractionation followed by separation by SDS-PAGE. (E) Scheme of the $175 \mathrm{kDa}$ complex centered on VDAC. In physiological conditions, P-VDAC interacts with $\mathrm{BcL}-\mathrm{X}_{\mathrm{L}}$ and GSK3, protecting the mitochondria from Cyt $c$ release.

\section{Figure 7. Pharmacological and genetic manipulation of GSK3 phosphorylation} modulates VDAC phosphorylation and mitochondrial sensitivity to $\mathrm{Ca}^{2+}$

(A) Phosphorylation of VDAC and GSK3 in isolated mitochondria from lean and $o b / o b$ mice liver. Proteins were immunoblotted for VDAC, GSK3, P-GSK3 and P-Thr and analyzed by densitometry. ${ }^{*} P<0.05$ vs. lean mice. (n=4) (B) Effect of 24 h-treatment of HHL-5 cells with $2 \mathrm{mM}$ FA +/- $2 \mathrm{~h}$ pre-treatment with $20 \mu \mathrm{M}$ SB216367 or $200 \mathrm{nM}$ Wortmannin (Wort) on phosphorylation of VDAC and GSK3. Total proteins were analyzed by immunoblotting and 
densitometry (means $\pm \mathrm{SD},{ }^{*} P<0.05$ and $\left.{ }^{* *} P<0.01\right)(\mathrm{n}=4)$. (C) Effect of kinase inhibitors on the transmembrane potential of HHL-5 (rhodamine 123 fluorescence arbitrary units) cells treated or not with $2 \mathrm{mM} F A$ in response to $25 \mu \mathrm{M} \mathrm{Ca}^{2+}$ addition at $\mathrm{t}_{0}(\mathrm{n}=10)\left({ }^{*} P<0.05\right.$ and $\left.{ }^{* *} P<0.01\right)(\mathrm{n}=3)$. (D) Silencing of GSK3 by a pool of 4 siRNAs for $48 \mathrm{~h}$ decreases VDAC phosphorylation in HH5 cells as shown by immunoblotting. Scramble siRNA is a negative control. Densitometry (arbitrary units) is given under each band. Results are representative of 3 independent experiments.

\section{REFERENCES}

1. Chiappini F, Barrier A, Saffroy R, Domart M, Dagues N, Azoulay D, Sebagh M, Franc B, Chevalier S, Debuire B, Dudoit S, Lemoine A. Exploration of global gene expression in human liver steatosis by high-density oligonucleotide microarray. Lab Invest 2006;86:154-65.

2. Hebbard L, George J. Animal models of nonalcoholic fatty liver disease. Nat Rev Gastroenterol Hepatol 2011;8:35-44.

3. McCullough A. Pathophysiology of nonalcoholic steatohepatitis. J Clin Gastroenterol 2006;40:S17-29.

4. Pessayre D. Role of mitochondria in non-alcoholic fatty liver disease. J Gastroenterol Hepatol 2007;22:S20-7.

5. Kroemer G, Galluzzi L, Brenner C. Mitochondrial membrane permeabilization in cell death. Physiol Rev 2007;87:99-163.

6. Rostovtseva T, Colombini M. VDAC channels mediate and gate the flow of ATP: implications for the regulation of mitochondrial function. Biophys J 1997;72:1954-62.

7. Koren I, Raviv Z, Shoshan-Barmatz V. Downregulation of voltage-dependent anion channel-1 expression by RNA interference prevents cancer cell growth in vivo. Cancer Biol Ther 2010;9:1046-52.

8. Maldonado E, Patnaik J, Mullins M, Lemasters J. Free tubulin modulates mitochondrial membrane potential in cancer cells. Cancer Res 2010;70:10192-201.

9. Baker MA, Lane DJ, Ly JD, De Pinto V, Lawen A. VDAC1 is a transplasma membrane NADH-ferricyanide reductase. J Biol Chem 2004;279:4811-9.

10. Clayton R, Rinaldi A, Kandyba E, Edward M, Willberg C, Klenerman P, Patel A. Liver cell lines for the study of hepatocyte functions and immunological response. Liver Int 2005;25:389-402.

11. Ricchi M, Odoardi M, Carulli L, Anzivino C, Ballestri S, Pinetti A, Fantoni L, Marra F, Bertolotti M, Banni S, Lonardo A, Carulli N, Loria P. Differential effect of oleic and palmitic acid on lipid accumulation and apoptosis in cultured hepatocytes. $\mathrm{J}$ Gastroenterol Hepatol 2009;24:830-40.

12. Jacotot E, Ravagnan L, Loeffler M, Ferri KF, Vieira HL, Zamzami N, Costantini P, Druillennec S, Hoebeke J, Briand JP, Irinopoulou T, Daugas E, Susin SA, Cointe D, Xie ZH, Reed JC, Roques BP, Kroemer G. The HIV-1 viral protein R induces 
apoptosis via a direct effect on the mitochondrial permeability transition pore. J Exp Med 2000;191:33-46.

13. Halaas J, Gajiwala K, Maffei M, Cohen S, Chait B, Rabinowitz D, Lallone R, Burley $\mathrm{S}$, Friedman J. Weight-reducing effects of the plasma protein encoded by the obese gene. Science 1995;269:543-6.

14. Elimadi A, Jullien V, Tillement J, D. M. S-15176 inhibits mitochondrial permeability transition via a mechanism independent of its antioxidant properties. Eur J Pharmacol 2003;468:93-101.

15. Morin D, Zini R, Berdeaux A, Tillement J. Effect of the mitochondrial transition pore inhibitor, S-15176, on rat liver mitochondria: ATP synthase modulation and mitochondrial uncoupling induction. Biochem Pharmacol 2006;72:911-8.

16. Hiller S, Garces R, Malia T, Orekhov V, Colombini M, Wagner G. Solution structure of the integral human membrane protein VDAC-1 in detergent micelles. Science 2008;321:1206-10.

17. Shoshan-Barmatz V, Keinan N, Zaid H. Uncovering the role of VDAC in the regulation of cell life and death. J Bioenerg Biomembr 2008;40:183-91.

18. Cross D, Alessi D, Vandenheede de J, McDowell H, Hundal H, Cohen P. The inhibition of glycogen synthase kinase-3 by insulin or insulin-like growth factor 1 in the rat skeletal muscle cell line L6 is blocked by wortmannin, but not by rapamycin: evidence that wortmannin blocks activation of the mitogen-activated protein kinase pathway in L6 cells between Ras and Raf. Biochem J 1994;303: 21-6.

19. Cross D, Culbert A, Chalmers K, Facci L, Skaper S, Reith A. Selective smallmolecule inhibitors of glycogen synthase kinase-3 activity protect primary neurones from death. J Neurochem 2001;77:94-102.

20. Wullaert A, van Loo G, Heyninck K, Beyaert R. Hepatic tumor necrosis factor signaling and nuclear factor-kappaB: effects on liver homeostasis and beyond. Endocr Rev 2007;28:365-86.

21. Malhi H, Kaufman R. Endoplasmic reticulum stress in liver disease. J Hepatol 2011;54:795-809.

22. Sahai A, Malladi P, Pan X, Paul R, Melin-Aldana H, Green R, Whitington P. Obese and diabetic $\mathrm{db} / \mathrm{db}$ mice develop marked liver fibrosis in a model of nonalcoholic steatohepatitis: role of short-form leptin receptors and osteopontin. Am J Physiol Gastrointest Liver Physiol 2004;287:G1035-43.

23. Tan W, Colombini M. VDAC closure increases calcium ion flux. Biochim Biophys Acta 2007; 1768:2510-5.

24. Báthori G, Csordás G, Garcia-Perez C, Davies E, Hajnóczky G. Ca2+-dependent control of the permeability properties of the mitochondrial outer membrane and voltage-dependent anion-selective channel (VDAC). J Biol Chem 2006;281:17347-58.

25. Koch-Nolte F, Fischer S, Haag F, Ziegler M. Compartmentation of NAD+-dependent signalling. FEBS Lett 2011;585:1651-6.

26. Tait S, Green D. Mitochondria and cell death: outer membrane permeabilization and beyond. Nat Rev Mol Cell Biol 2010;11:621-32.

27. Zhai P, Sadoshima J. Overcoming an energy crisis?: an adaptive role of glycogen synthase kinase-3 inhibition in ischemia/reperfusion. Circ Res 2008;103:910-3.

28. Dentin R, Benhamed F, Hainault I, Fauveau V, Foufelle F, Dyck J, Girard J, Postic C. Liver-specific inhibition of ChREBP improves hepatic steatosis and insulin resistance in ob/ob mice. Diabetes 2006;55:2159-70.

29. Das S, Wong R, Rajapakse N, E. M, Steenbergen C. Glycogen Synthase Kinase 3 Inhibition Slows Mitochondrial Adenine Nucleotide Transport and Regulates VoltageDependent Anion Channel Phosphorylation. Circ Res 2008;103:983-991. 
30. Pastorino J, Hoek J, Shulga N. Activation of glycogen synthase kinase 3beta disrupts the binding of hexokinase II to mitochondria by phosphorylating voltage-dependent anion channel and potentiates chemotherapy-induced cytotoxicity. Cancer Res 2005;65:10545-54.

31. Sheldon K, Maldonado E, Lemasters J, Rostovtseva T, Bezrukov S. Phosphorylation of voltage-dependent anion channel by serine/threonine kinases governs its interaction with tubulin. PLoS One 2011;6:e25539.

32. Taniguchi C, Emanuelli B, Kahn C. Critical nodes in signalling pathways: insights into insulin action. Nat Rev Mol Cell Biol 2006;7:85-96.

33. Capeau J. Insulin resistance and steatosis in humans. Diabetes Metab 2008;34:649-57.

34. Liquori G, Calamita G, Cascella D, Mastrodonato M, Portincasa P, Ferri D. An innovative methodology for the automated morphometric and quantitative estimation of liver steatosis. Histol Histopathol 2009;24:49-60.

35. Griffiths EJ, Halestrap AP. Protection by Cyclosporin A of ischemia/reperfusioninduced damage in isolated rat hearts. J Mol Cell Cardiol 1993;25:1461-9.

36. Tarze A, Deniaud A, Le Bras M, Maillier E, Molle D, Larochette N, Zamzami N, Jan G, Kroemer G, Brenner C. GAPDH, a novel regulator of the pro-apoptotic mitochondrial membrane permeabilization. Oncogene 2006;26:2606-20.

37. Gincel D, Silberberg S, Shoshan-Barmatz V. Modulation of the voltage-dependent anion channel (VDAC) by glutamate. J Bioenerg Biomembr 2000;32:571-83.

38. Deniaud A, Rossi C, Berquand A, Homand J, Campagna S, Knoll W, Brenner C, Chopineau J. Voltage-dependent anion channel transports calcium ions through biomimetic membranes. Langmuir 2007;23:3898-905.

39. van Heeswij $\mathrm{M}$, van Os C. Osmotic water permeabilities of brush border and basolateral membrane vesicles from rat renal cortex and small intestine. J Membr Biol 1986;92:183-93.

40. Fiskum G, Kowaltowksi A, Andreyev A, Kushnareva Y, Starkov A. Apoptosis-related activities measured with isolated mitochondria and digitonin-permeabilized cells. Methods Enzymol 2000;322:222-34.

41. Wittig I, Braun H, Schägger H. Blue native PAGE. Nat Protoc 2006;1:418-28.

\section{ACKNOWLEDGMENTS}

C. Longin from the microscopy and imagery platform of INRA is acknowledged. Dr A. Patel, University of Glasgow, UK, is acknowledged for his generous gift of HHL-5 hepatocyte cell line. We are grateful to S. Campagna and N. Saint for the electrophysiological measurements.

We thank C. Gallerne and E. Maillier for technical assistance. BCl- $\mathrm{X}_{\mathrm{L}}$ was a gift from Alexandre Chenal (Institut Pasteur, Paris) and Christine Almunia (CEA Marcoule, direction

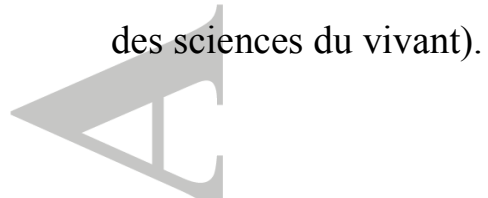

\section{FUNDING}


CB is supported by the University of Paris Sud (grant attractivité), Institut National pour le Cancer (INCa, 2008-1-PL BIO-04-CNRS ON1) and LabEx LERMIT. CB and AL are supported by the PRES UniverSud Paris. CM received a fellowship from Association pour la Recherche sur le Cancer. CB, MA and JC are supported by ANR (ANR-08PCVI-0008-01). GC gratefully acknowledges financial support from MIUR (PRIN20089SRS2X_003) and Fondazione Cassa di Risparmio di Puglia.

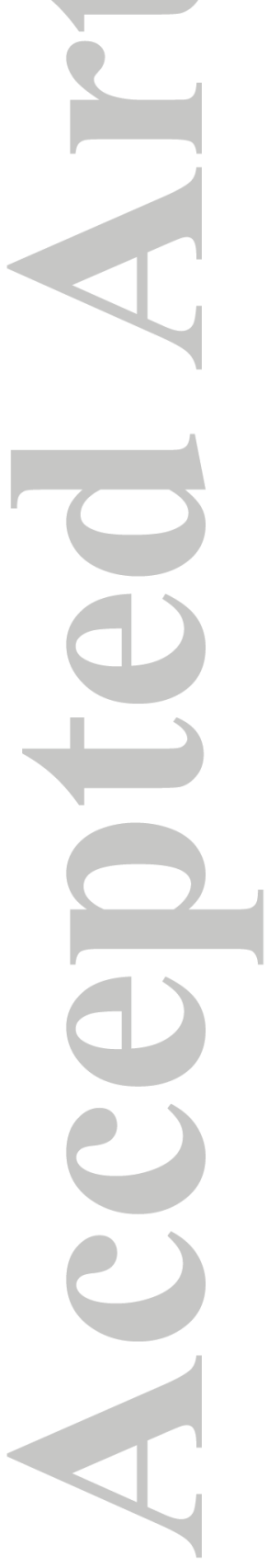



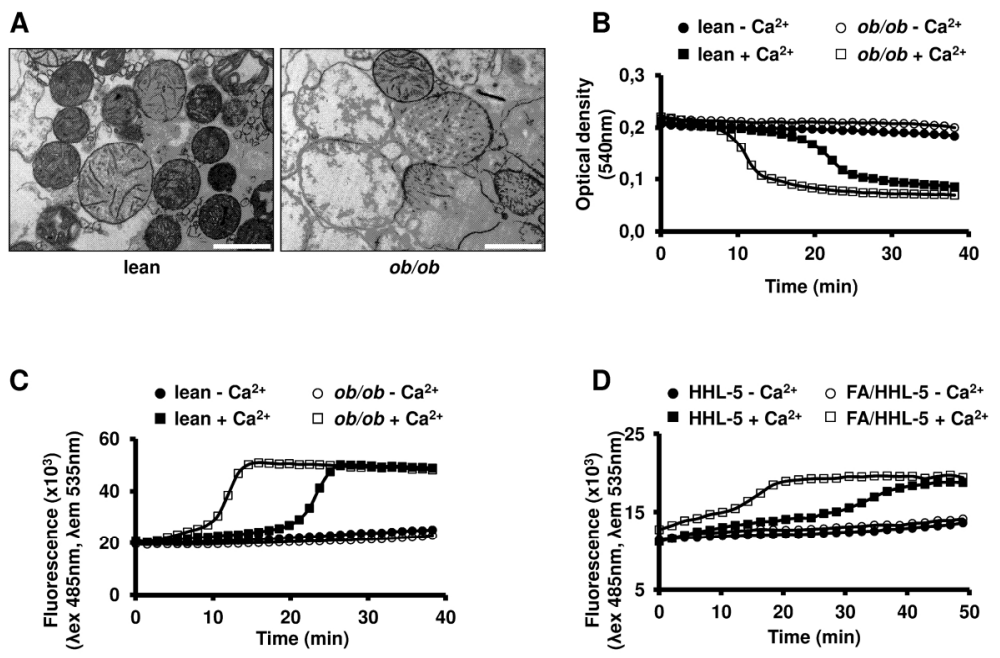

Figure 1

$209 \times 148 \mathrm{~mm}(300 \times 300$ DPI $)$ 

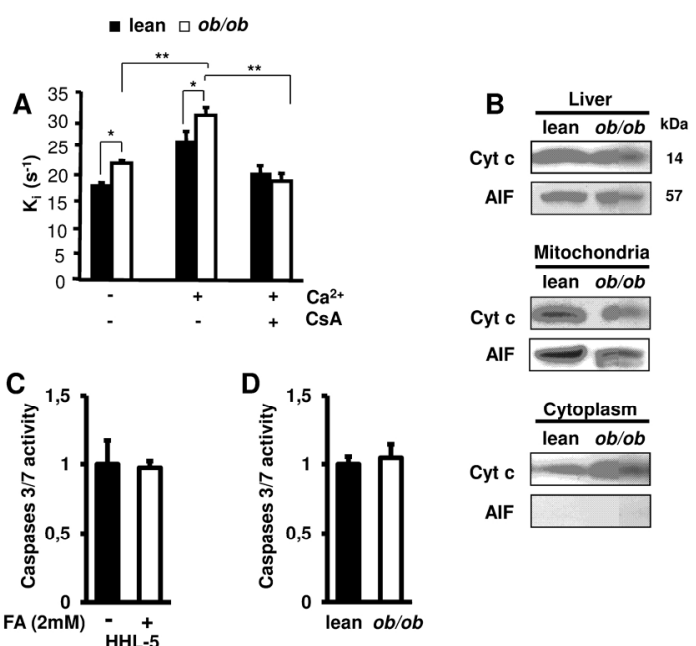

Figure 2

209x148mm (300 x 300 DPI) 

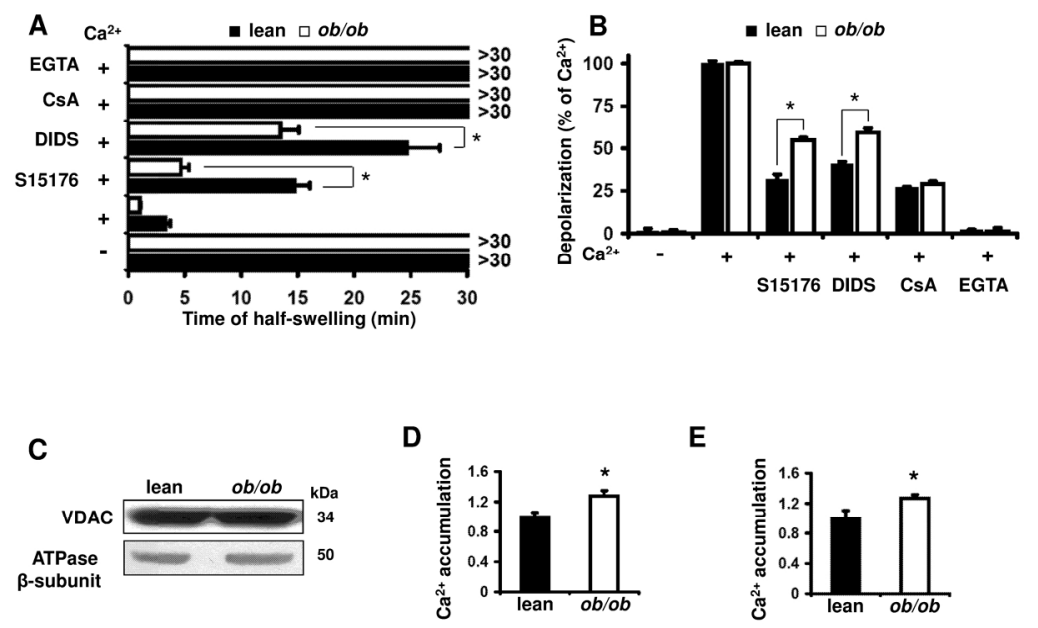

Figure 3

$209 \times 148 m m(300 \times 300$ DPI $)$ 


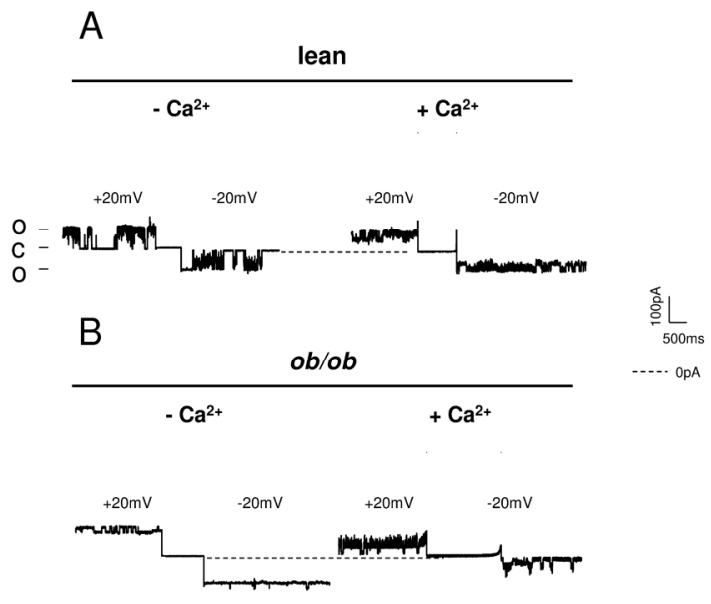

Figure 4

$209 \times 148 \mathrm{~mm}(300 \times 300$ DPI $)$ 

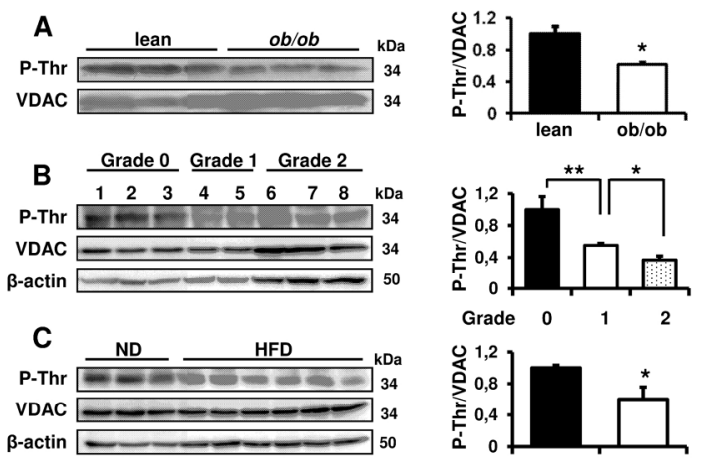

$$
\text { D }
$$
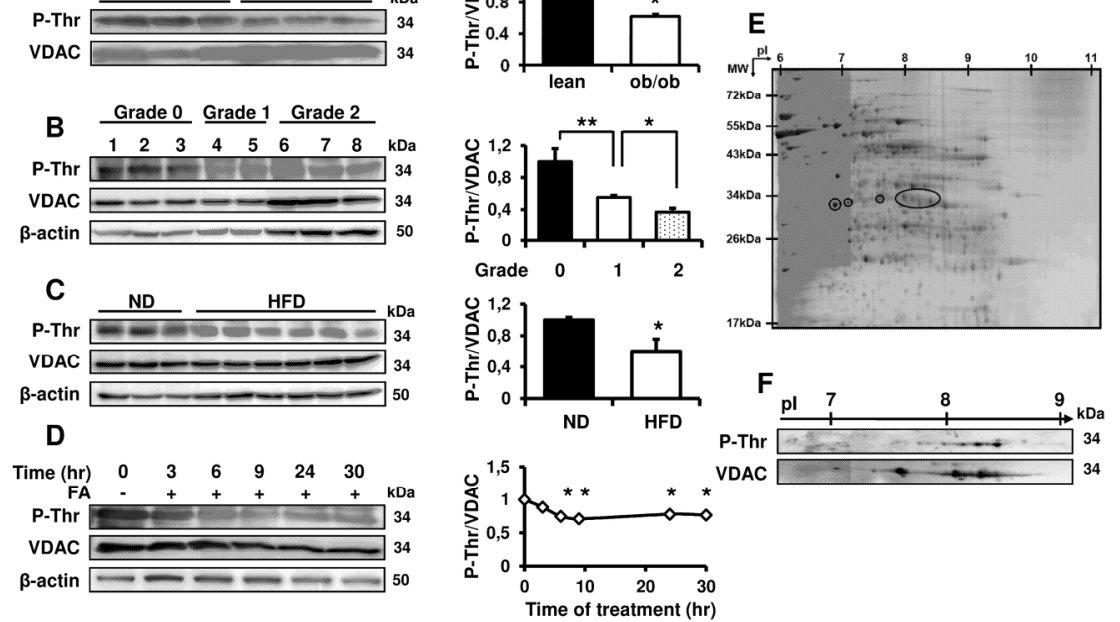

Figure 5

209x148mm (300 x 300 DPI) 

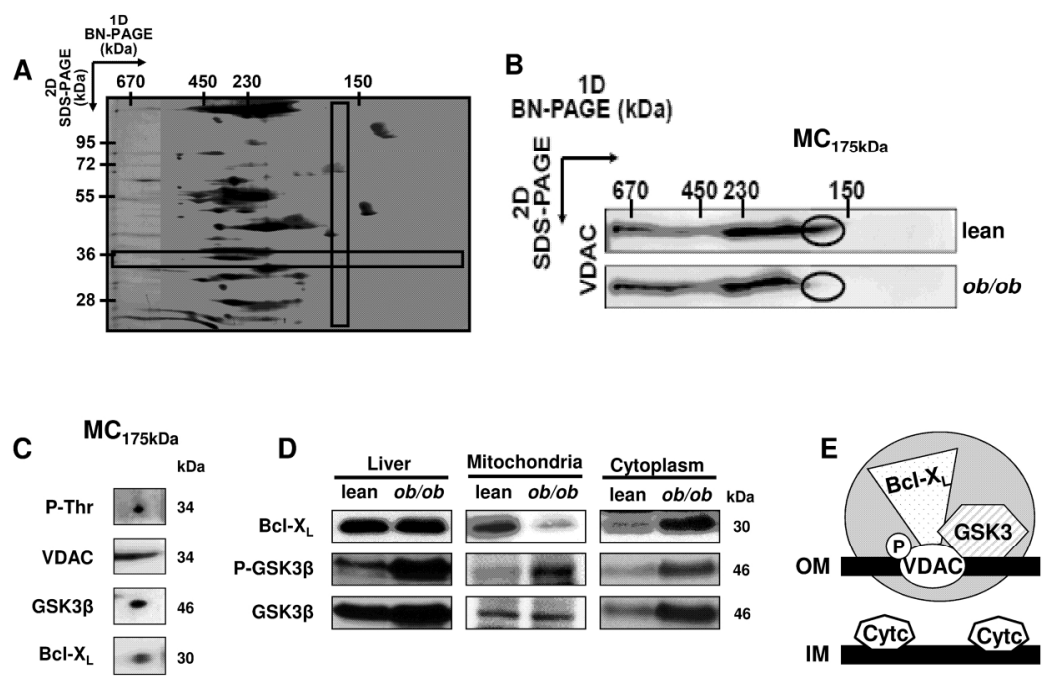

Figure 6

209x148mm (300 x 300 DPI) 

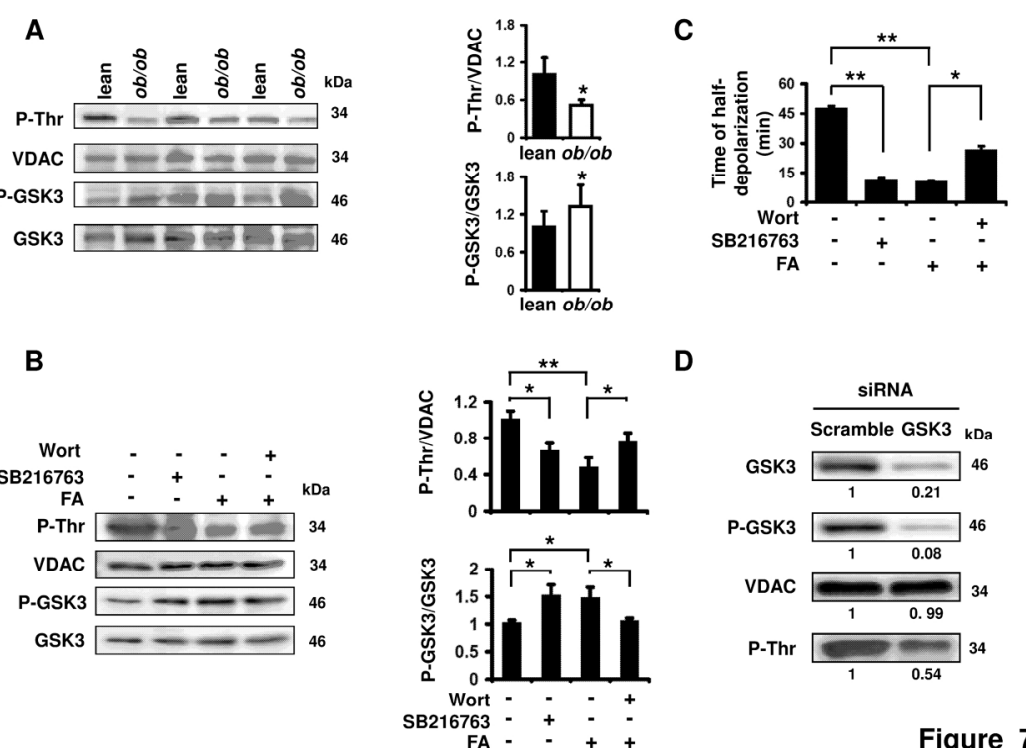

Figure 7

$209 \times 148 m m(300 \times 300$ DPI $)$ 


\section{GSK3-mediated VDAC phosphorylation controls outer mitochondrial membrane} permeability during lipid accumulation

Cecile MARTEL ${ }^{1,2}$, Maya ALLOUCHE ${ }^{3}$, Davide DEGLI ESPOSTI ${ }^{2}$, Elena FANELLI ${ }^{4}$, Céline BOURSIER $^{5}$, Céline HENRY ${ }^{6}$, Joel CHOPINEAU ${ }^{3,7}$, Giuseppe CALAMITA ${ }^{4}$ Guido KROEMER $^{8-12}$, Antoinette LEMOINE ${ }^{2 *}$, Catherine BRENNER ${ }^{1^{*}}$

\section{SUPPLEMENTARY MATERIALS AND METHODS}

\section{Materials}

All cell culture reagents were purchased from Invitrogen (Paisley, Scotland, UK). When not indicated, chemicals were from Sigma (St. Louis, MO).

\section{Animal models}

Female 6-12 weeks old lean (C57BL/6J) and $o b / o b(\mathrm{~B} 6 . \mathrm{V}-\mathrm{Lepob} / \mathrm{J})$ mice were purchased from Janvier (Le Genest Saint Isle, France). Male 4-week-old C57BL/6J mice (Harlan, Udine, Italy) were acclimatized to laboratory conditions for one week before being randomly assigned to either the high fat or standard chow diet (Altromin-Rieper, Vandoies, Italy). The high fat (HFD; 42\% of saturated fat; 70\% calories from fat; kJ) and standard (non diet, ND; $4 \%$ of saturated fat; $10 \%$ calories from fat; $\mathrm{kJ}$ ) diets were provided in small pellets for 25 weeks.

\section{Animal tissue collection}

Mice were maintained in a 12-hour day/night cycle at controlled room temperature and provided free access to food and water. Five mice of each group were sacrificed at week 25 after being placed on the respective diet. Blood was collected just before sacrifice for serum biochemical analysis. Livers were quickly excised, cleaned completely with ice-cold phosphate-buffered saline (PBS), and preserved in liquid nitrogen until use. Pieces of the 
remaining liver tissues were processed by histochemistry for the assessment of the degree of liver steatosis by employing an automated method ${ }^{34}$. The protocol was conducted according to the Guide Principles for the care and use of laboratory animals.

\section{Collection of human liver biopsies}

Eight frozen biopsies were chosen among liver biopsies collected during graft harvesting in our institution. Steatosis was graded by two pathologists, depending on the percentage of cells presenting lipid vacuoles in their cytoplasm, in grade $0(<5 \%)$, grade $1(5-30 \%)$ and grade 2 $(30-60 \%)$. The study protocol follows the recommendations of the ethical guidelines of the 1975 Declaration of Helsinki and was approved by our ethical committee.

\section{Cell culture}

HHL-5, immortalized non-cancerous primary hepatocytes (a generous gift from Dr A. Patel, University of Glasgow, UK) ${ }^{10}$ are cultured in DMEM-F12 (Dulbecco's Modified Eagle's Medium) supplemented with $10 \%$ fetal bovine serum, $1 \%$ glutamax and $1 \%$ penicillin/streptomycin, in $5 \% \mathrm{CO}_{2}$ at $37^{\circ} \mathrm{C}$. To induce lipid vacuoles formation, the usual culture medium was supplemented with $2 \%$ BSA and $2 \mathrm{mM}$ oleate/palmitate $(2: 1$ ratio), as described in the literature ${ }^{11}$ and the cells were treated with this medium for 3 to $30 \mathrm{~h}$.

\section{Isolation of mouse liver mitochondria}

Mitochondria were isolated from the liver of lean or $o b / o b$ mice in an iso-osmotic buffer $(0.3$ M sucrose, $5 \mathrm{mM}$ TES, $0.2 \mathrm{mM}$ EGTA, $1 \%$ BSA, $5 \mathrm{mM}$ sodium fluoride, $1 \mathrm{mM}$ sodium pyrophosphate, $1 \mathrm{mM}$ sodium orthovanadate, $\mathrm{pH}$ 7.2) by differential centrifugation and

purified on Percoll gradient according to a previous work ${ }^{12}$. The cytosolic fraction (supernatant) was then obtained by centrifugation at $100.000 \mathrm{x}$ g for $1 \mathrm{~h}$ at $4^{\circ} \mathrm{C}$. 


\section{Transmission electron microscopy}

Isolated mitochondria were fixed in $4 \%$ glutaraldehyde, $0.1 \mathrm{M}$ sodium cacodylate for $1 \mathrm{~h}$ at room temperature (RT) and then, washed in 0.1 sodium cacodylate, $0.4 \mathrm{M}$ sucrose for $1 \mathrm{~h}$ at RT. Samples were then paraffin-embedded, sliced, mounted on slides and the images were obtained at the electron microscopy facility (INRA, Jouy-en-Josas, France).

\section{Enzymatic assays on mouse liver mitochondria}

All assays were performed in 96 -well plates $(200 \mu \mathrm{l})$ at $37^{\circ} \mathrm{C}$ in a spectrofluorimeter (TECAN genios, TECAN, Austria). For absorbance and optical density measurements, transparent microplates were used and for fluorescent measurement, black microplates were used. Mitochondria $(25 \mu \mathrm{g}$ of proteins $/ 200 \mu \mathrm{l})$ were diluted in a hypo-osmotic buffer (10 mM TrisMOPS, pH 7.4, $5 \mathrm{mM}$ succinate, $200 \mathrm{mM}$ sucrose, $1 \mathrm{mM}$ Pi, $10 \mu \mathrm{M}$ EGTA, $2 \mu \mathrm{M}$ freshlyadded rotenone). Various doses of $\mathrm{Ca}^{2+}$, considered as a PT inducer, were added. Several pharmacological inhibitors, such as EGTA, a $\mathrm{Ca}^{2+}$ chelator, CsA, PTP inhibitor ${ }^{35}$, DIDS, which targets VDAC ${ }^{25}$ and S-15176, a PTP inhibitor ${ }^{14,15}$ were added to mitochondrial suspension concomitantly with $\mathrm{Ca}^{2+}$ or not. Simultaneously, the mitochondrial swelling was immediately measured by the decrease in optical density at $540 \mathrm{~nm}$ and the depolarization of the mitochondria was measured by the rhodamine $123(1 \mu \mathrm{M})$ fluorescence dequenching $(\lambda$ ex: 485nm, $\lambda \mathrm{em}: 535 \mathrm{~nm}$, Molecular Probes) ${ }^{36} \cdot \mathrm{Ca}^{2+}$ entry in the mitochondrial matrix was measured by fluorescence using rhodamine $2(\lambda \mathrm{ex}=540 \mathrm{~nm}$ and $\lambda \mathrm{em}=595 \mathrm{~nm})$. For NADH oxidase activity of VDAC, mitochondria $(10 \mu \mathrm{g})$ were incubated $10 \mathrm{~min}$ at $37^{\circ} \mathrm{C}$ with or

without several doses of DIDS (10 to $80 \mu \mathrm{M})$. Then, $250 \mu \mathrm{M}$ NADH was added 15 min before the addition of $300 \mu \mathrm{M}$ ferricyanide to start the reaction. NADH oxidase activity was 
measured by following the decrease of fluorescence of NADH $(\lambda \mathrm{ex}=360 \mathrm{~nm}, \lambda \mathrm{em}=465 \mathrm{~nm}$, adapted from ${ }^{9}$.

\section{Native VDAC purification}

VDAC was purified from mitochondria from lean and $o b / o b$ livers ${ }^{37}$. Briefly, mitochondria $(5 \mathrm{mg} / \mathrm{ml})$ were lysed by osmotic chock in $10 \mathrm{mM}$ Tris, $\mathrm{pH} 7.0$ for $30 \mathrm{~min}$ and centrifuged $1 \mathrm{~h}$ at $100.000 \mathrm{x}$ g. The pellet containing the mitochondrial membranes was solubilized $(5 \mathrm{mg} / \mathrm{ml}$ of protein) in $10 \mathrm{mM}$ Tris,3\% Triton $\mathrm{X}-100, \mathrm{pH} 7$ for $30 \mathrm{~min}$ and centrifuged $1 \mathrm{~h}$ at $100.000 \mathrm{x}$ g. All steps were performed at $4^{\circ} \mathrm{C}$. The supernatant containing the mitochondrial membrane proteins was loaded onto a dry hydroxyapatite/celite (2:1) column, and then VDAC was collected in the flow through. Purity of VDAC purification was verified by SDS-PAGE, followed by silverstain or immunodetection.

\section{Recombinant VDAC}

His-tagged hVDAC1 was produced in E. coli XL-1 Blue strain (Agilent, U.S.) using a pQE30-rhVDAC1 construct. Protein production was induced by addition of $1 \mathrm{mM}$ IPTG for 4 h at $37^{\circ} \mathrm{C}$. The bacteria were collected and the biomass was suspended in buffer A $(1: 50 \mathrm{v} / \mathrm{v}$, $20 \mathrm{mM}$ Tris, $\mathrm{pH} 7.9,200 \mathrm{mM} \mathrm{NaCl}$ and $1 \mathrm{mM}$ PMSF). After homogenization by pulse sonication, the inclusion bodies were washed extensively in buffer A before being solubilized in buffer $\mathrm{B}(1: 20 \mathrm{v} / \mathrm{v}, 6 \mathrm{M}$ urea- $\mathrm{HCl}, 20 \mathrm{mM}$ Tris- $\mathrm{HCl}, \mathrm{pH} 7.9,500 \mathrm{mM} \mathrm{NaCl}$, and $10 \%$ glycerol) at $4^{\circ} \mathrm{C}$. Denatured hVDAC1 was collected by centrifugation at $18,000 \times \mathrm{g}$ for 20 $\underline{\text { min. The protein was purified using a Ni NTA resin (Qiagen, Germany) pre-equilibrated with }}$ buffer B. After extensive washing the rhVDAC1-bound resin, elution was performed with a

linear gradient of imidazole $(10$ to $300 \mathrm{mM})$. Glycerol and imidazole were removed and the $\underline{\text { concentration of } \mathrm{NaCl} \text { was lowered to } 50 \mathrm{mM} \text { by dialysis. hVDACl in denaturing buffer was }}$ 
refolded by drop wise dilution at $4^{\circ} \mathrm{C}$ with stirring into refolding buffer $(25 \mathrm{mM}$ sodium phosphate $\mathrm{pH} 7.0,100 \mathrm{mM} \mathrm{NaCl}, 1 \mathrm{mM}$ EDTA, $5 \mathrm{mM}$ DTT, 2\% lauryl dimethylamine oxide (LDAO)) to yield a final protein: detergent micelle ratio of $\sim 1: 20$. After overnight stirring at $\underline{4^{\circ} \mathrm{C} \text { the refolded VDAC sample was dialyzed against phosphate buffer to remove urea. }}$

The protein purity was verified by $10 \%$ SDS-PAGE by staining with Coomassie brilliant blue G-250. The protein concentrations were determined using using BCA assay with bovine serum albumin as the standard. The pure rhVDAC 1 concentration was about $0.5 \mathrm{mg} / \mathrm{ml}$.

$\underline{\text { To assess hVDAC1 correct folding and activity, we performed CD measurements and BLM }}$ single channels measurements. In the presence of $0.5 \mathrm{mM} \mathrm{Ca}^{2+}$ the classical hallmarks of $\underline{\text { VDAC were observed; at low membrane potentials (below } 30 \mathrm{mV} \text { ) (a permanently open state }}$ $\underline{\text { with a single-full conductance of about } 2600 \text { to } 3000 \mathrm{pS} \text { in } 1 \mathrm{M} \mathrm{KCl} \text { was observed. At higher }}$ voltages closing events and numerous subconductance states were observed.

\section{Planar lipid bilayer experiments}

Planar lipid bilayers were formed by painting phosphatidylcholine from soy beans (azolectin from Sigma type IV S) dissolved in decane $(30 \mathrm{mg} / \mathrm{ml})$ across a $200-\mu \mathrm{m}$ aperture in a polysulfonate cup (Warner Instruments) separating 2 chambers $1.2 \mathrm{~mL}$ each. The trans chamber compartment was connected to the headstage input of a bilayer voltage clamp amplifier (BLM 120, Biologic). The cis chamber was held at virtual ground. Voltages were applied to the planar lipid bilayers through $\mathrm{Ag}-\mathrm{AgCl}$ electrodes connected to the chambers via agar $/ \mathrm{KCl}$ bridges. Both cis and trans chamber solutions were composed of $1 \mathrm{M} \mathrm{KCl}, 10 \mathrm{mM}$ HEPES (N-2-hydroxyethylpiperazine-N'-2-ethanesulfonic acid), pH 7.4 with or without $0.5 \mathrm{mM} \mathrm{CaCl}_{2}$. 3-4 $\mu$ l of purified VDAC from lean and $o b / o b$ mice (initial concentration of $0.2-0.3 \mathrm{mg} / \mathrm{ml}$ ) were diluted 50 -fold in $1 \%$ octyl-polyoxyethylene and added to the ciscompartment. Single VDAC channels were reconstituted spontaneously upon addition of the 
protein to the solution. For analysis, the data were filtered to $1 \mathrm{kHz}$, digitized at $4 \mathrm{kHz}$ and collected on a Pentium computer using Axoxcope10 (Molecular Devices) and a digidata 1440A (Molecular Devices). Data were analyzed with Clampfit 9.0.

\section{$\mathrm{Ca}^{2+}$ transport in proteoliposomes}

$\mathrm{Ca}^{2+}$ entry through VDAC pores into proteoliposomes was measured by following the increase of the fluorescence of fluo-4-dextran at $\lambda \mathrm{ex}=485 \mathrm{~nm}, \lambda \mathrm{em}=535 \mathrm{~nm}$ for $30 \mathrm{~min}^{38}$.

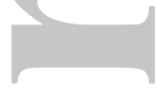

\section{Stopped flow light scattering}

Mitochondria from lean or obese mice were subjected rapidly to a hypertonic osmotic gradient of $140 \mathrm{mOsm}$ created by mannitol, and the time course of the related shrinkages was followed at $20^{\circ} \mathrm{C}$ from the increase in scattered light $(\lambda=450 \mathrm{~nm})$ using a BioLogic MPS-200 (BioLogic, Italy) stopped-flow reaction analyzer (dead time of $1.6 \mathrm{~ms}$; 99\% mixing efficiency in $<1 \mathrm{~ms}$ ). The data were fitted to a single exponential function and the related rate constant $(\mathrm{Ki}, \mathrm{s}-1)$ of the water efflux out of the mitochondria, a biophysical parameter correlated to the organelle membrane water permeability ${ }^{39}$ was measured. The medium osmolarity was verified by freezing point depression, using a Halbmikro-Osmometer (Knauer, Berlin, Germany). In some experiments, mitochondria were incubated for $10 \mathrm{~min}$ in the presence or the absence of $25 \mu \mathrm{M} \mathrm{Ca}^{2+}$ prior the osmotic upshock. In another series, $1 \mu \mathrm{M} \mathrm{CsA}$ was added or not to the mitochondrial suspensions 5 min before the $\mathrm{Ca}^{2+}$ treatment.

\section{NADH-ferricyanide reductase activity}

The NADH-ferricyanide reductase activity of VDAC from lean and $o b / o b$ mice was measured according to ${ }^{38}$. 


\section{Lipid labeling}

Lipid vacuoles were stained with the fluorescent probe Nile Red. Briefly, after treatment, cells were washed in PBS, incubated with $100 \mu \mathrm{M}$ Nile Red in HBSS (Hank's Buffered Salt Solution) for $20 \mathrm{~min}$ at $37^{\circ} \mathrm{C}$ and washed in PBS. Fluorescence of Nile Red was measured in white microplates of 96 wells in a spectrofluorimeter (Genios TECAN) at $\lambda \mathrm{ex}=552 \mathrm{~nm}$, $\lambda$ em $=636 \mathrm{~nm}$ or micrographs were taken on a Leica fluorescence microscope (cells were previously seeded on slides).

\section{Mitochondrial membrane depolarization in permeabilized cells}

Mitochondrial membrane depolarization, in permeabilized cells, was determined using rhodamine 123 in permeabilized cells (adapted from ${ }^{40}$ ).

\section{RNA interference}

Cells were cultured in 6-well plates and transfected at $70 \%$ confluence by using DharmaFECT 4 reagent (Dharmacon), with small interfering RNAs (siRNAs) specifically targeting human GSK3 $\beta$ (ON-TARGETplus SMARTpool GSK3B, Dharmacon) or the control (ON-TARGETplus Non-targeting pool, Dharmacon) for $48 \mathrm{~h}$.

\section{Caspase $3 / 7$ assays}

Active caspase-3/7 was determined with Apo-ONE homogenous Caspase-3/7 Assay (Promega, Madison, WI, USA), following the manufacturer's instructions.

\section{SDS-PAGE and immunoblot}

Proteins $(30 \mu \mathrm{g})$ in Laemmli buffer were separated by sodium dodecyl-sufate polyacrylamide gel electrophoresis (SDS-PAGE) and transferred to PVDF membranes (Millipore). 
Membranes were incubated overnight at $4^{\circ} \mathrm{C}$ with the following antibodies: anti-VDAC and anti-ANT (polyclonal serum, Genosphere, Paris, France), anti-phosphothreonine, anti-GSK3, anti-phosphoGSK3 and Bcl-XL 54H6 (Cell Signaling), anti-AIF (Chemicon), anticytochrome $c$ (BD Biosciences), anti-ATPase $\beta$-subunit (Mitosciences), $\beta$-actin HRP (Santa Cruz). Proteins were detected on a Chemidoc XRS (Biorad) by using the ECL method according to the manufacturer's instructions (Millipore) and quantification of protein bands density was realized with Quantity One (BioRad).

\section{Two-dimensional gel electrophoresis}

Mitochondrial proteins were solubilized in $100 \mu \mathrm{L}$ of isoelectric focusing (IEF) solution (7 M urea, $2 \mathrm{M}$ thiourea and $1 \% \mathrm{w} / \mathrm{v}$ Triton-X100). Proteins were centrifuged at $10.000 \mathrm{x} g$ for 10 min. The supernatant was quantified with 2-D Quant kit (GE Healthcare, VélizyVillacoublay, France). The first dimension IEF was performed on $18 \mathrm{~cm}$ dry strips $\mathrm{pH}$ 6-11 (GE-Healthcare). IEF was performed on Protean IEF Cell (BioRad, Marnes la Coquette, France). Prior to SDS-PAGE, $12 \%$ polyacrylamide gels $(1 \times 170 \times 250 \mathrm{~mm})$ were prepared in EttanDALTsix Gel Caster (GE Healthcare) and strips were positioned at the surface of the SDS-PAGE gel. SDS-PAGE was carried out in EttanDALTsix (GE Healthcare) as following: $80 \mathrm{~V}, 10 \mathrm{~mA} / \mathrm{gel}, 1 \mathrm{~W} / \mathrm{gel}$ for $30 \mathrm{~min}$ and $600 \mathrm{~V}, 40 \mathrm{~mA} / \mathrm{gel}, 13 \mathrm{~W} / \mathrm{gel}$. Gels were then washed in $\mathrm{ddH}_{2} \mathrm{O}$ for $5 \mathrm{~min}$ and fixed in $40 \%$ ethanol/7\% acetic acid solution for $1 \mathrm{~h}$ before SyproRuby (BioRad) staining over night in the dark. Gels were scanned with Typhoon 9400 (GE Healthcare) using ImageQuant software (GE Healthcare). Gels were stained with colloïdal Coomassie Blue (GE Healthcare) and scanned with ImageScanner (GE Healthcare) using LabScan software (GE Healthcare). 


\section{D BN-PAGE}

2D Blue Native (BN) PAGE was carried out, as previously described in ${ }^{41}$. Briefly, mitochondria (2 mg) from lean and $o b / o b$ mice liver were centrifuged for $10 \mathrm{~min}$ at $6.800 \mathrm{xg}$ at $4^{\circ} \mathrm{C}$ and resuspended in a lysis buffer $(750 \mathrm{mM}$ aminocaproic acid, $50 \mathrm{mM}$ bis-Tris, $2 \mathrm{mM}$ EDTA, 1\% Triton X-100, $5 \mathrm{mM}$ sodium fluoride, $1 \mathrm{mM}$ sodium pyrophosphate, $1 \mathrm{mM}$ sodium orthovanadate) for $30 \mathrm{~min}$ at $4^{\circ} \mathrm{C}$. Mitochondrial proteins were centrifuged for $15 \mathrm{~min}$ at $72.000 \times \mathrm{g}$ (airfuge, Beckman) and the protein concentration of the supernatant was determined using the micro-BCA assay (Pierce, Illinois). Mitochondrial proteins $(50 \mu \mathrm{g})$ in loading buffer (5\% glycerol and $0.3 \%$ Coomassie blue) were loaded in a 4-15\% BN-PAGE gradient gel (BioRad) and the migration was carried for $2-3 \mathrm{~h}$ at $50 \mathrm{~mA}$. The BN gel strips were cut with a scalpel and denatured in $120 \mathrm{mM}$ Tris pH 6.8, 20\% glycerol, 4\% SDS, 100 $\mathrm{mM}$ dithiothreitol (DTT), $0.02 \%$ bromophenol blue for $10 \mathrm{~min}$ at $95^{\circ} \mathrm{C}$. The strips were loaded in a $12 \%$ SDS-PAGE gel and a classic SDS-PAGE migration was carried out, followed by Western-blot or silverstain.

\section{Mass spectrometry analysis}

In-gel digestion was performed according to a standard trypsin protocol. Gel pieces were washed twice by successive separate baths of 50/50 ammonium carbonate $\left(\mathrm{NH}_{4} \mathrm{CO}_{3}\right) 50 \mathrm{mM}$ and acetonitrile (ACN). Gels were dried and reduction with $10 \mathrm{mM}$ DTT in $25 \mathrm{mM} \mathrm{NH}_{4} \mathrm{CO}_{3}$ and alkylation with $55 \mathrm{mM}$ iodoacetamide in $25 \mathrm{mM} \mathrm{NH}_{4} \mathrm{CO}_{3}$ were performed. Digestion was subsequently performed for $6 \mathrm{~h}$ at $37^{\circ} \mathrm{C}$ with $100 \mathrm{ng}$ of modified trypsin (Promega) dissolved in $50 \mathrm{mM} \mathrm{NH}_{4} \mathrm{CO}_{3}$. The peptides were extracted successively with $0.5 \%$ trifluoroacetic acid (TFA) and 50\% ACN. Peptide extracts were dried in a vacuum centrifuge and suspended in $20 \mu \mathrm{L}$ of $0.05 \% \mathrm{TFA}, 0.05 \%$ formic acid, and $2 \% \mathrm{ACN}$. HPLC was performed on an Ultimate 3000 LC system (Dionex). A $4 \mu 1$ sample was loaded at $20 \mu 1 /$ min- 1 on a precolumn cartridge 
(stationary phase: C18 PepMap 100, $5 \mu \mathrm{m}$; column: $300 \mu \mathrm{m}$ i.d., 5 mm; Dionex) and desalted with $0.08 \%$ TFA and $2 \%$ ACN. After 4 min, the precolumn cartridge was connected to the separating PepMap C18 column (stationary phase: C18 PepMap 100, $3 \mu \mathrm{m}$; column: $75 \mu \mathrm{m}$ i.d., $150 \mathrm{~mm}$; Dionex). Buffers were 0.1\% $\mathrm{HCOOH}, 2 \% \mathrm{ACN}(\mathrm{A})$ and $0.1 \% \mathrm{HCOOH}$ and $80 \%$ ACN (B). The peptide separation was achieved with a linear gradient from 0 to $36 \% \mathrm{~B}$ for $18 \mathrm{~min}$ at $300 \mathrm{nl} / \mathrm{min}-1$. Including the regeneration step at $100 \% \mathrm{~B}$ and the equilibration step at $100 \% \mathrm{~A}$, one run took 50 min. Eluted peptides were analysed on-line with a LTQOrbitrap mass spectrometer (Thermo Electron) using a nanoelectrospray interface. Ionization $(1.3 \mathrm{kV}$ ionization potential) was performed with liquid junction and a capillary probe $(10 \mu \mathrm{m}$ i.d.; New Objective). Peptide ions were analysed using Xcalibur 2.07 with the following datadependent acquisition steps (1): full MS scan in orbitrap (mass-to-charge ratio $(\mathrm{m} / \mathrm{z}) 300$ to 1600 , profil mode) and (2) MS/MS in linear trap (qz $=0.25$, activation time $=30 \mathrm{~ms}$, and collision energy $=45 \%$; centroid mode). Step 2 was repeated for the four major ions detected in step 1. Dynamic exclusion time was set to $90 \mathrm{~s}$. A database search was performed with XTandem 2010.01.01.4 (http://www.thegpm.org/TANDEM/).

\section{In vitro phosphorylation}

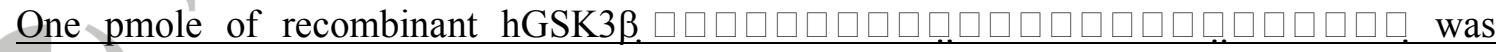
added to 0.1 pmole of mVDAC, $\mathrm{hVDAC}$ and $\mathrm{hBcl}-\mathrm{X}_{\mathrm{L}}$ in the presence of $625 \mathrm{pmol}$ ATP in a buffer containing $25 \mathrm{mM}$ MOPS, $\mathrm{pH} 7.2,12.5 \mathrm{mM}$ glycerol $25 \mathrm{mM} \mathrm{MgCl} 2,5 \mathrm{mM}$ EGTA, 2 $\underline{\mathrm{mM} \text { EDTA and } 0.25 \mathrm{mM} \text { DTT. The mix was incubated for } 30 \mathrm{~min} \text { at } 30^{\circ} \mathrm{C} \text { under mild }}$ stirring, heat-inactived and ATP was quantified by bioluminescence in microtiter plates as indicated (Kit ATP HS II, Roche, USA). Controls (Co.) were determined by omission of the kinase in VDAC and Bcl-XL-containing samples in each experiments, blanks (0) were 
determined by omission of ATP and maximal phosphorylation was obtained with a synthetic substrate (S, SignalChem, Interchim, France).

\section{$\underline{\text { Immunohistology }}$}

Four livers samples, two from control female mice and two from ob/ob mice were obtained for immunostaining experiments. Immunohistology was performed on $4 \mu \mathrm{m}$ paraffin embedded formalin fixed liver sections using a mouse anti-human cytochrome c (BD Biosciences, Franklin Lake, NJ, USA). Antigen retrieval was obtained by heat at $97^{\circ} \mathrm{C}$ in a citrate buffer at $\mathrm{pH}$ 6. The revelation system was based on a one-step biotin free immunoperoxydase stain (Envision, DAKO, Glostrup, Denmark) using 3,3-diaminobenzidine (DAB) chromogene (DAKO, Glostrup, Denmark) substrate followed by Hemalun counterstaining. Negative controls for each slide were processed concurrently with probed samples by omitting primary antibody.

\section{Statistical analysis}

Data were analyzed using Student's t-test for all pair-wise comparisons of growth rates and mean responses to the different treatments tested. Results are presented as the mean \pm standard deviation (SD) of replicates experiments. Significance: *: $p<0.05,{ }^{*}$ : $p<0.01$. 
Supplementary Table 1. NADH oxidase activity of VDAC is enhanced in ob/ ob mice.

VDAC NADH oxidase activity was measured by a colorimetric enzymatic assay $(\lambda=340 \mathrm{~nm})$ on VDAC purified from isolated mitochondria from lean and ob/ob mice in the presence and absence of $500 \mu \mathrm{M} \mathrm{Ca} 2+(\mathrm{n}=3)$. Enzymatic initial rates were calculated from the linear part of the curve using a molar extinction coefficient of $6220 \mathrm{M}-1 . \mathrm{cm}-1$ for $\mathrm{NADH}$ and expressed in $\mathrm{nmol} / \mathrm{min} / \mathrm{mg}$. $\mathrm{n}=3$.

\begin{tabular}{ccc}
\hline & $\begin{array}{c}\text { NADH oxidase activity } \\
\text { without } \mathrm{Ca}^{2+}(\mathrm{nmol} / \\
\mathrm{min} / \mathrm{mg})\end{array}$ & $\begin{array}{c}\mathrm{NADH} \text { oxidase activity } \\
\text { with } \mathrm{Ca}^{2+}(\mathrm{nmol} / \mathrm{min} / \\
\mathrm{mg})\end{array}$ \\
\hline lean & 346.8 & 277.23 \\
ob/ob & 600.82 & 1128.02 \\
\hline
\end{tabular}

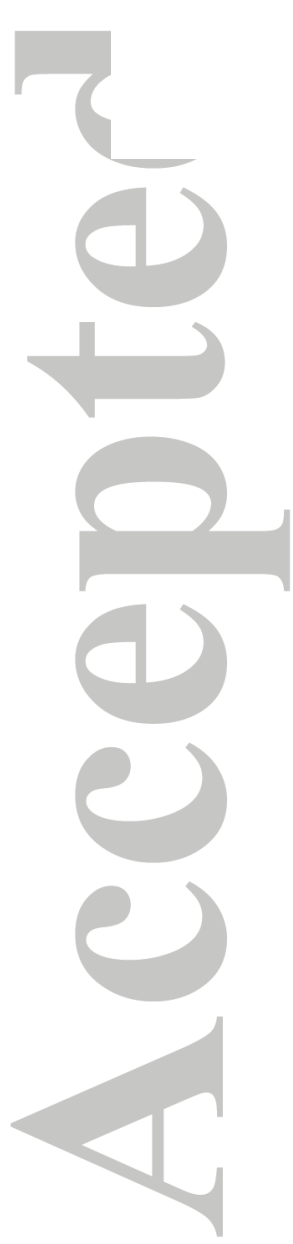


Supplementary Table 2. Electrophysiological characteristics of VDAC purified from liver of lean and $o b / o b$ mice in presence of phosphatase inhibitors. Characterisitics have been calculated from current traces presented in Figure 5. Dwell time, opening time (ms). Interevent, time between each event. -, no experimental data. $\mathrm{N}$, number of events for main (C1) and secondary (C2) amplitude level.

\begin{tabular}{|c|c|c|c|c|c|c|c|c|c|}
\hline VDAC & Conditions & $\begin{array}{l}\text { Amplitude } \\
\text { levels }\end{array}$ & $\begin{array}{c}\text { Main } \\
\text { amplitude, } \\
\mathrm{Cl}(\mathrm{pA})\end{array}$ & $\begin{array}{l}\text { Main } \\
\text { dwell } \\
\text { time } \\
(\mathrm{ms})\end{array}$ & $\begin{array}{c}\text { Main } \\
\text { interevent } \\
(\mathrm{ms})\end{array}$ & $\begin{array}{c}\text { Secondary } \\
\text { amplitude, } \\
\text { C2 (pA) }\end{array}$ & $\begin{array}{l}\text { Secondary } \\
\text { dwell time } \\
\text { (ms) }\end{array}$ & $\begin{array}{c}\text { Secondary } \\
\text { interevent } \\
\text { (ms) }\end{array}$ & $\begin{array}{l}\mathrm{N} \text { for } \\
\mathrm{Cl} / \mathrm{C} 2\end{array}$ \\
\hline \multirow[t]{4}{*}{ lean } & $-\mathrm{Ca}^{2+}+20 \mathrm{mV}$ & 1 & $70 \pm 13$ & 92 & 200 & - & - & - & $105 / 0$ \\
\hline & $-\mathrm{Ca}^{2+}-20 \mathrm{mV}$ & 1 & $-54 \pm 8$ & 10 & 159 & - & - & - & $103 / 0$ \\
\hline & $+\mathrm{Ca}^{2+}+20 \mathrm{mV}$ & 2 & $108+21$ & 141 & 144 & $62 \pm 9$ & 24 & 445 & $15 / 47$ \\
\hline & $+\mathrm{Ca}^{2+}-20 \mathrm{mV}$ & 2 & $-100 \pm 15$ & 205 & 218 & $-69 \pm 6$ & 9 & 1640 & $21 / 21$ \\
\hline \multirow[t]{4}{*}{$a b / o b$} & $-\mathrm{Ca}^{2+}+20 \mathrm{mV}$ & 2 & 96 & 17383 & - & $16 \pm 0.7$ & 63 & 1053 & $1 / 11$ \\
\hline & $-\mathrm{Ca}^{2+}-20 \mathrm{mV}$ & 1 & -104 & 18536 & - & - & - & - & $1 / 0$ \\
\hline & $+\mathrm{Ca}^{2+}+20 \mathrm{mV}$ & 2 & $42 \pm 4$ & 144 & 169 & $20+3$ & 1.33 & 56 & $39 / 439$ \\
\hline & $+\mathrm{Ca}^{2+}-20 \mathrm{mV}$ & 1 & $-5 \pm 1$ & 20 & 195 & - & - & - & $102 / 0$ \\
\hline
\end{tabular}

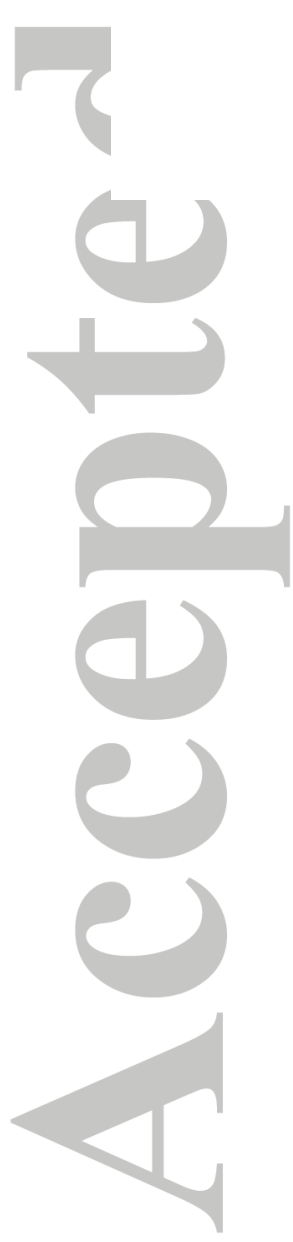


Supplementary Table 3. Clinical and histological features of liver donors. When present, inflammation is always represented by polymorphonuclear infiltrates. Severity of inflammation is graded as absent, mild, moderate or severe.

\begin{tabular}{|c|c|c|c|c|c|c|c|c|c|}
\hline Patient & Sex & Age $(y$ & $\begin{array}{l}\text { Body Mass } \\
\text { Index } \\
\left(\mathrm{kg} / \mathrm{m}^{2}\right)\end{array}$ & AST (IU/L) & ALT (IUIL) & GammaGT (IULL) & $\begin{array}{l}\text { Total Bilirubin } \\
\text { (micromol/L) }\end{array}$ & $\begin{array}{l}\text { Steatosis } \\
\text { (grade) }\end{array}$ & Inflammation \\
\hline 1 & $F$ & 44 & 22.5 & 79 & 39 & 38 & 5 & nu skatosis 60 & absont \\
\hline 2 & $\mathrm{~F}$ & 65 & 24.6 & 14 & 24 & 41 & 12 & nu stectosis 0 jo & absenl \\
\hline 3 & $M$ & 54 & 25.6 & 30 & 28 & 21 & 2 & no skeatosis 00 & absent \\
\hline 4 & $M$ & 64 & 23.4 & 42 & 21 & 17 & 21 & $\begin{array}{c}\text { Steatosc Macro } \\
10 \% \text { micio } 5 \%(1)\end{array}$ & abscnt \\
\hline 5 & $M$ & 45 & 38.9 & $4 /$ & 33 & 18 & 11 & 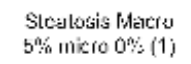 & mild \\
\hline 6 & M & 63 & 32.0 & 96 & 44 & 68 & 17 & $\begin{array}{l}\text { Steatosis Macro } \\
20 \% \text { micro } 15 \% \\
\text { (2) }\end{array}$ & mild \\
\hline 7 & $M$ & 49 & 24.8 & 53 & 15 & 8 & 8.9 & $\begin{array}{l}\text { Skcalosis bidero } \\
10^{\%} \text { micro } 4 \% \% \\
\text { (2) }\end{array}$ & absent \\
\hline 8 & $M$ & 54 & 26.2 & 68 & 65 & 76 & 5 & $\begin{array}{l}\text { Steatosis Macro } \\
30 \% \text { micro } 39 \% \\
\text { (2) }\end{array}$ & mild \\
\hline
\end{tabular}

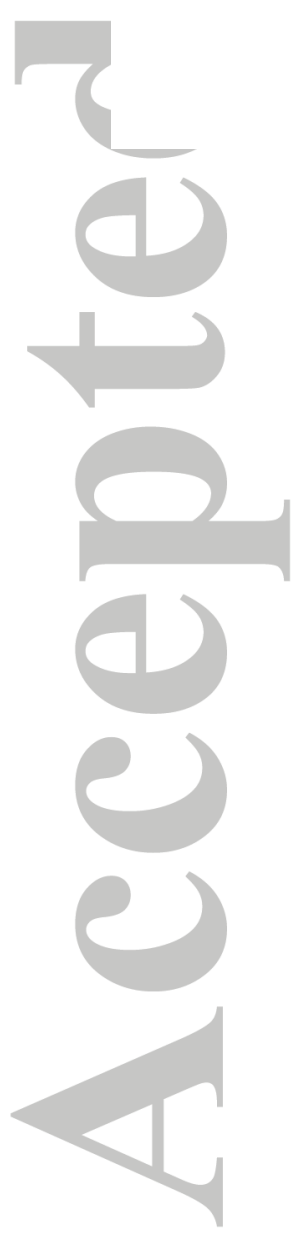


Supplementary Table 4. VDAC isoforms identification by $\mathrm{nLC} / \mathrm{ms} / \mathrm{ms} / \mathrm{ms}$. Mitochondrial proteins have been separated by 2D-SDS-PAGE. Spots co-identified by anti-VDAC and anti-P-Thr immunoblotting and peptides that have been identified by mass spectrometry are reported and the sequence coverage has been indicated $(\mathrm{n}=2)$.
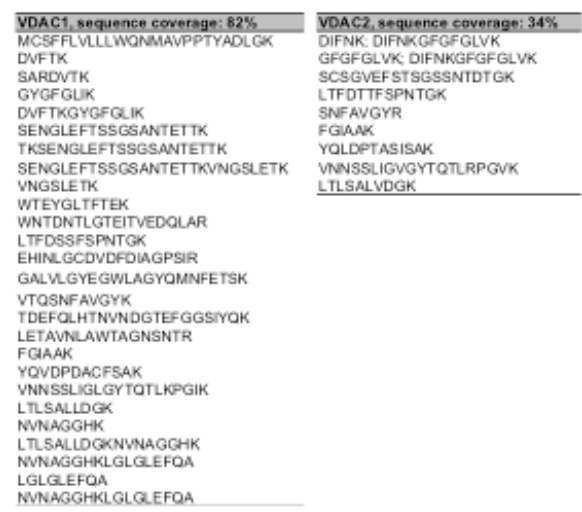

VDAC3, sequence coverage: $39 \%$

DWFNK

GYGFGMNK

VCNYGLTFTOK

LTLDTIFYPNTGK

LSONNFALGKK
IETSINLAWTAGSNNTR

FGAAK

LTSALVDGK

LTLSALIDGK
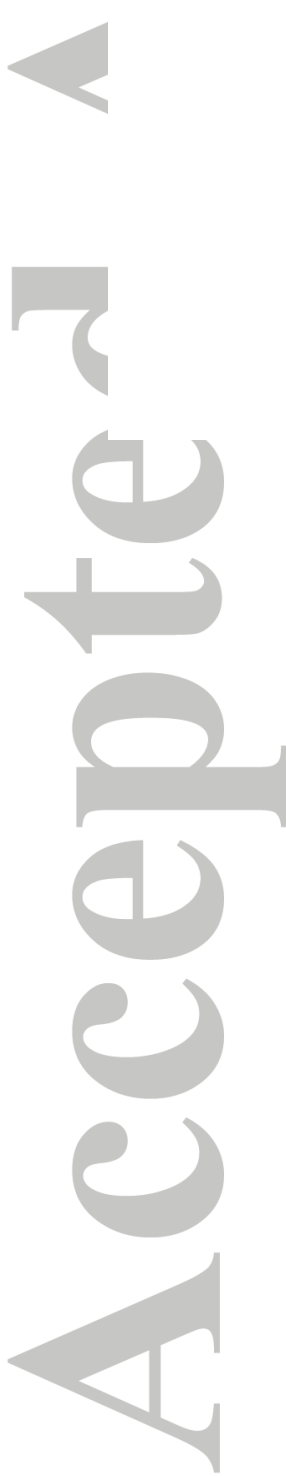

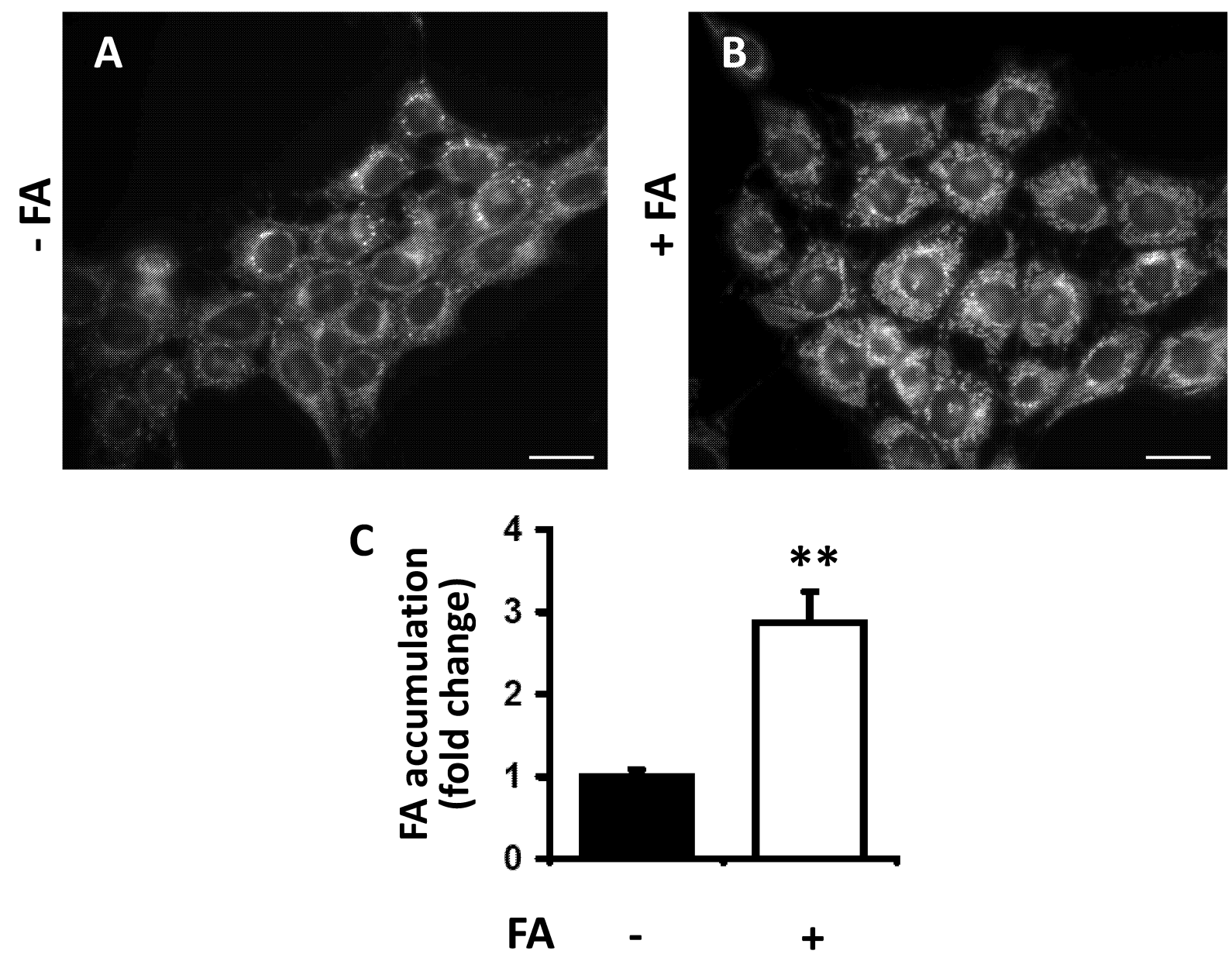

Supplementary Figure 1. Fatty acids (FA) accumulation in the cytoplasm of HHL-5 cells.

HHL-5 cells were treated with $2 \mathrm{mM} \mathrm{FA}$, stained with $100 \mathrm{nM}$ Nile Red for $30 \mathrm{~min}$ at $37^{\circ} \mathrm{C}$. Cells were observed by fluorescence microscopy $(\mathbf{A}, \mathbf{B})$ or total fluorescence $(\mathbf{C})$ was measured by fluorimetry (TECAN, $\lambda \mathrm{ex}=552 \mathrm{~nm}, \lambda \mathrm{em}=636 \mathrm{~nm}$ ) to quantify FA intracellular accumulation. $* * P<0.01 v s$. untreated $(-), \mathrm{n}=4$. Scale bar, $10 \mu \mathrm{M}$. 

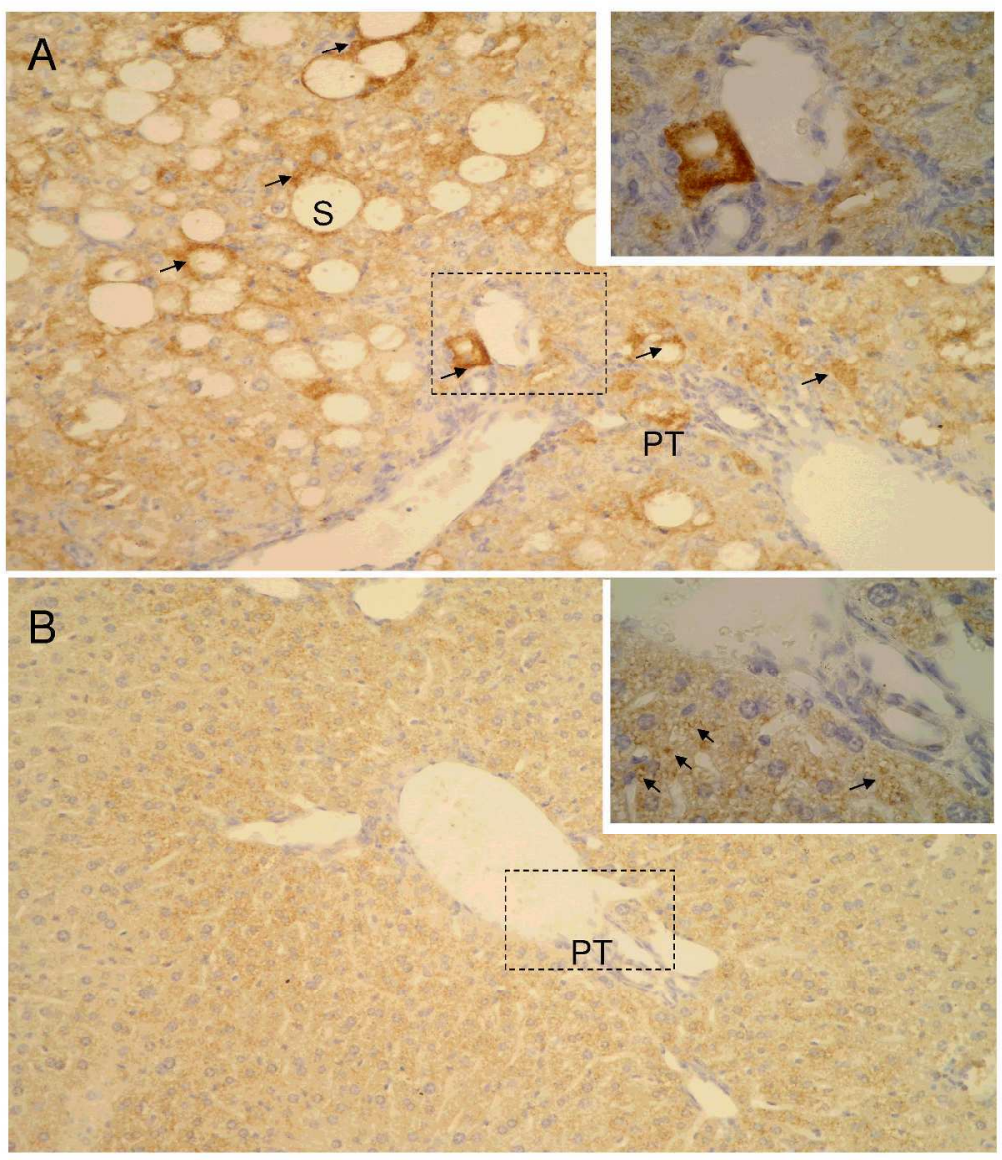

Supplementary Figure 2. A) Immunohistochemical staining of cytochrome $c$ (Cyt $c$ ) in a steatotic liver from $o b / o b$ mouse. Increased and diffuse cytoplasmic staining is observed in hepatocytes at portal tracts (PT) and in steatotic hepatocytes (S and black arrows) (400x and 1000x). B) Immunohistochemical staining of Cyt $c$ in a normal liver from wt mouse. Punctate and cytoplasmic staining is observed in particular in hepatocytes at portal tracts (black arrows) (200x and 1000x).

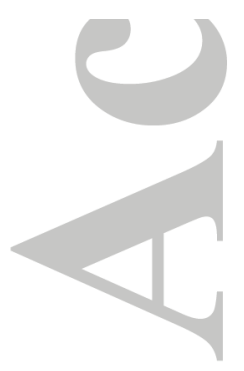

$209 \times 297 \mathrm{~mm}(300 \times 300 \mathrm{DPI})$ 


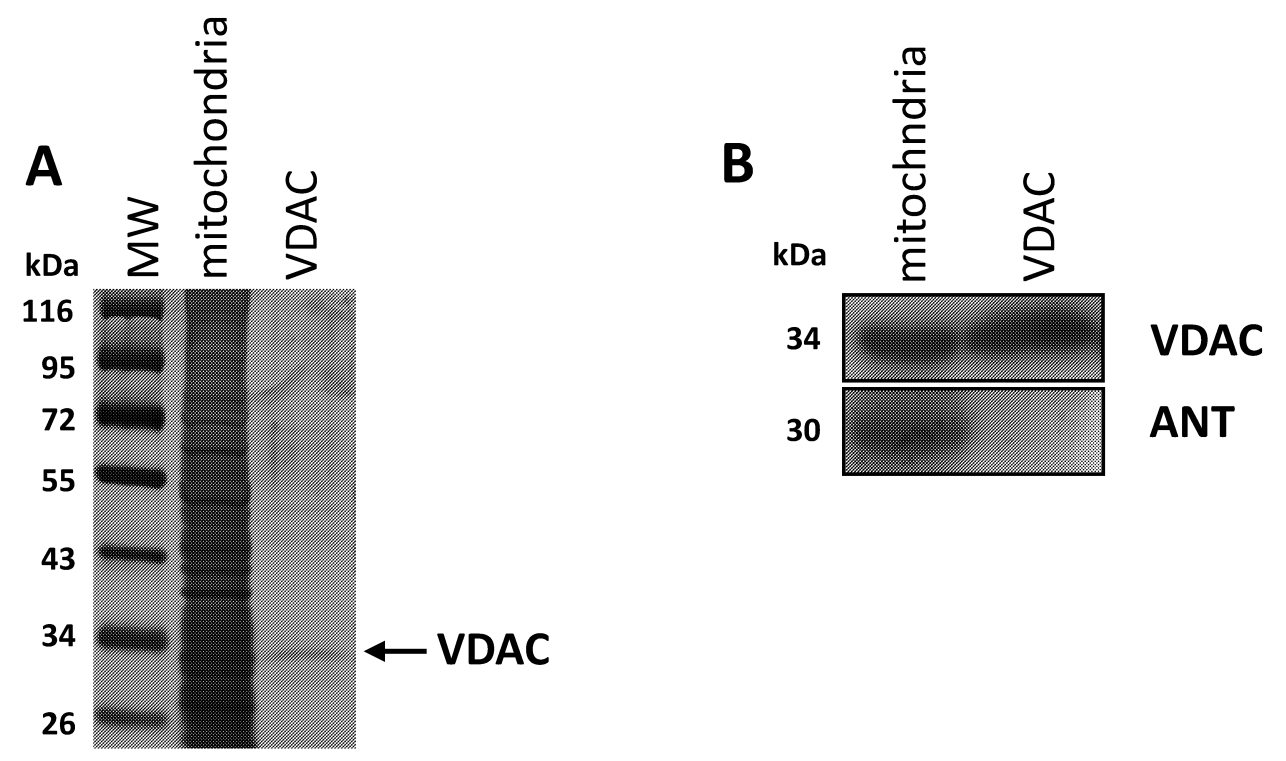

Supplementary Figure 3. Purification to homogeneity of mouse liver VDAC.

(A) Silverstain of a SDS-PAGE gel of $o b / o b$ mice liver mitochondrial proteins and purified VDAC. (B) The presence of VDAC and the absence of ANT in the purified fraction of VDAC. Proteins $(5 \mu \mathrm{g})$ were separated by SDS-PAGE and analyzed by immunoblotting. MW, molecular weight markers. One representative gel and one immunoblot of 3 independent experiments are shown. 

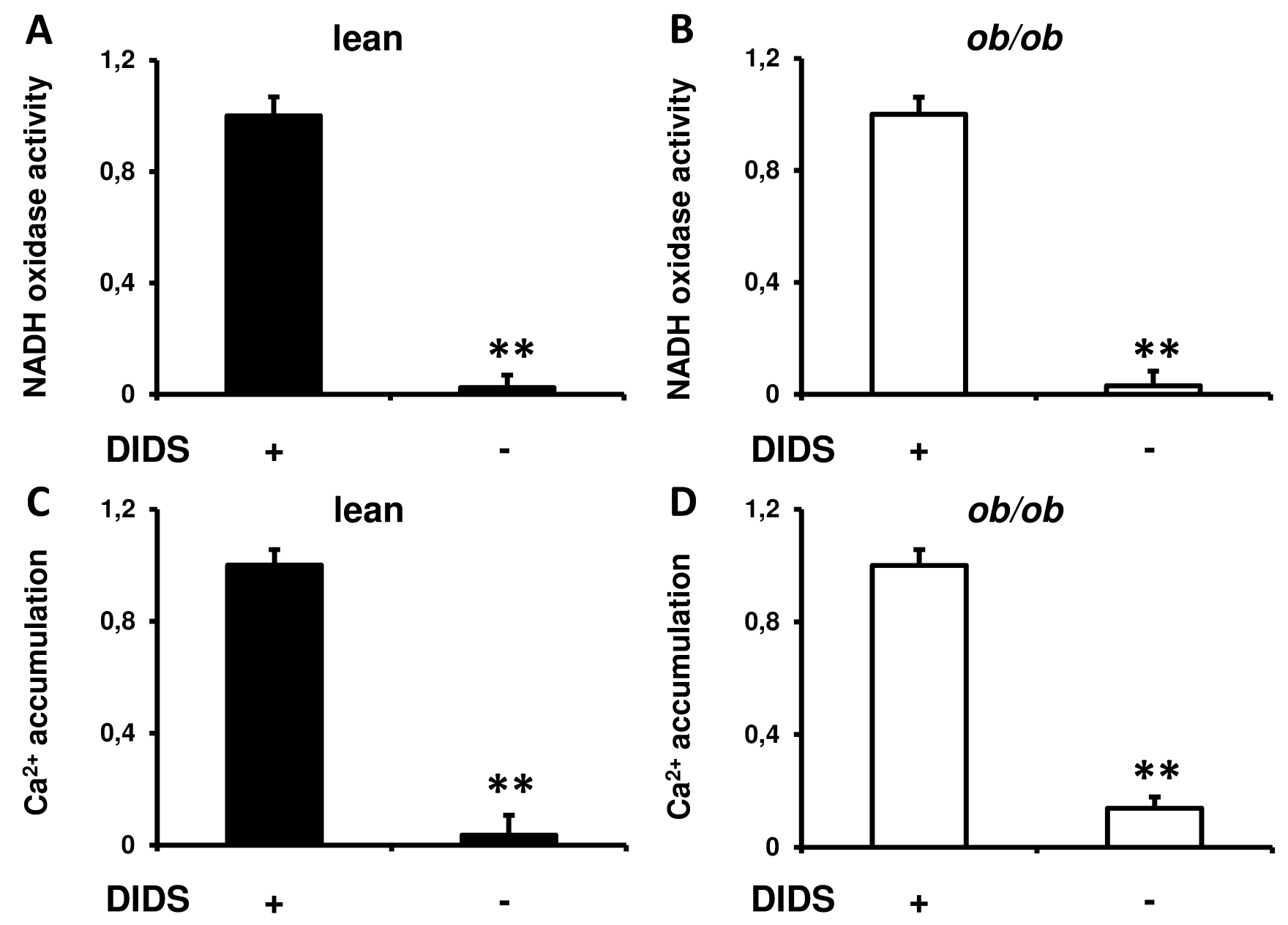

\section{Supplementary Figure 4. Effect of DIDS, a VDAC blocker, on VDAC functions.}

$(\mathbf{A}, \mathbf{B})$ Effect on NADH oxidase activity. Isolated mitochondria $(10 \mu \mathrm{g})$ from lean (A) and $o b / o b$ (B) mice liver were treated by $80 \mu \mathrm{M}$ DIDS and NADH oxidase activity of VDAC was measured by a colorimetric enzymatic assay $(\lambda=340 \mathrm{~nm}) .(\mathbf{C}, \mathbf{D}) \mathrm{Ca} 2+$ accumulation in the mitochondrial matrix of isolated mitochondria $(25 \mathrm{mg})$ from lean $(\mathbf{C})$ and $o b / o b(\mathbf{D})$ mice liver was determined by the fluorescent probe Rhod2 $(2 \mathrm{mM}$, lex $=549 \mathrm{~nm}$, lem $=$ $578 \mathrm{~nm}, 37^{\circ} \mathrm{C}, \mathrm{n}=3$ ). Mitochondria were exposed to $50 \mu \mathrm{M}$ DIDS prior to $25 \mu \mathrm{M} \mathrm{Ca} 2+$. $* * P<0.01 v s$. untreated (-). $\mathrm{n}=5$. Lean mice (black bars) and $o b / o b$ mice (white bars). 


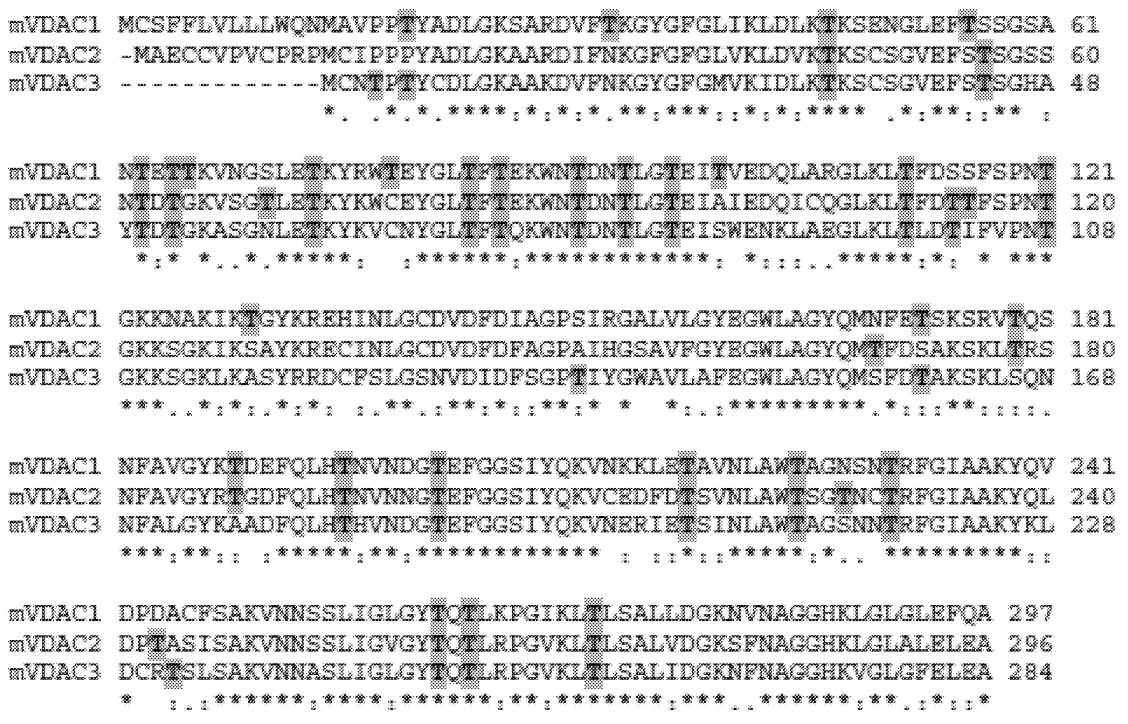

Supplementary Figure 5. Alignments of mouse VDAC protein sequences showing homologies and threonin residues $(\mathrm{T})$ in grey.

Sequences are from UniProtKB (mVDAC1, Q60932; mVDAC2, Q60930 and mVDAC3, Q60931). A star (*) indicates identical amino acids and a point (.) or a double point (:) indicates similar amino acids. 
A

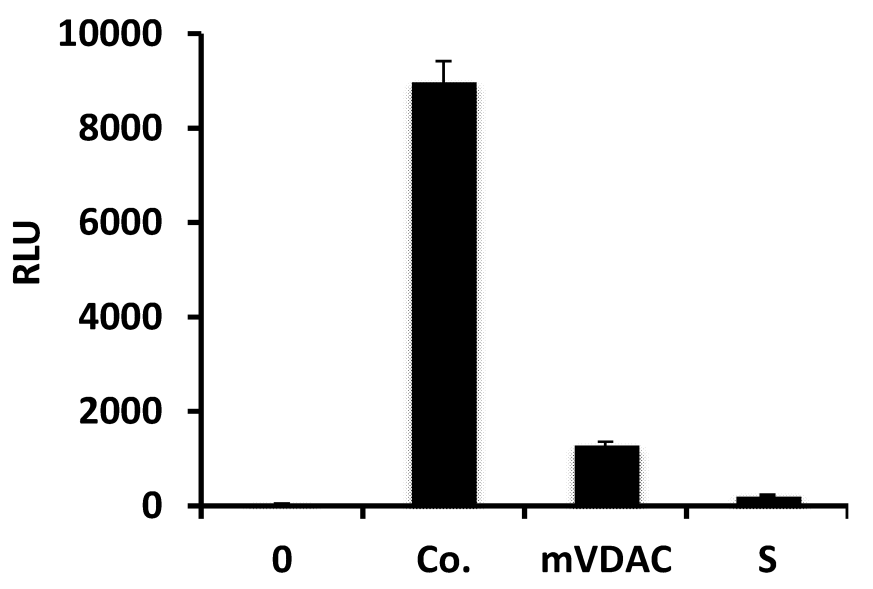

B

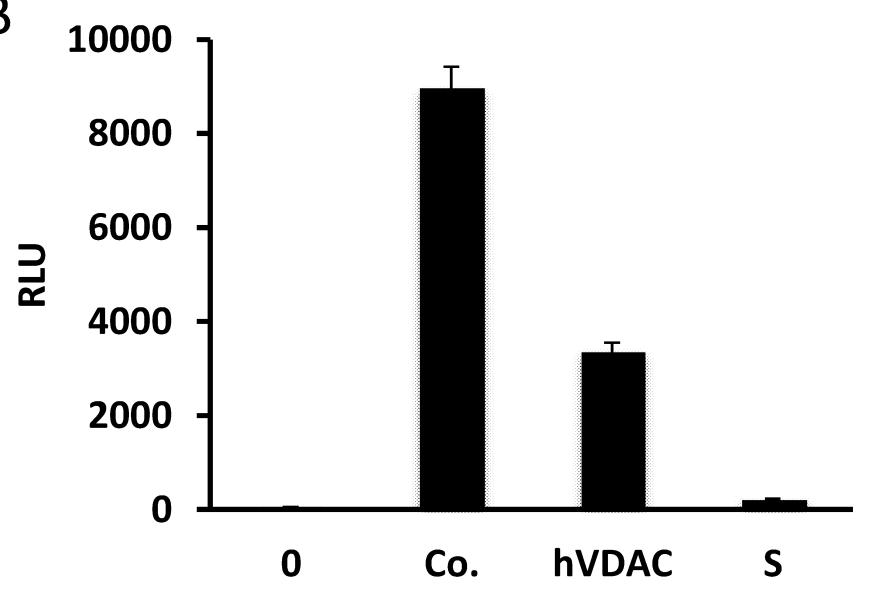

C

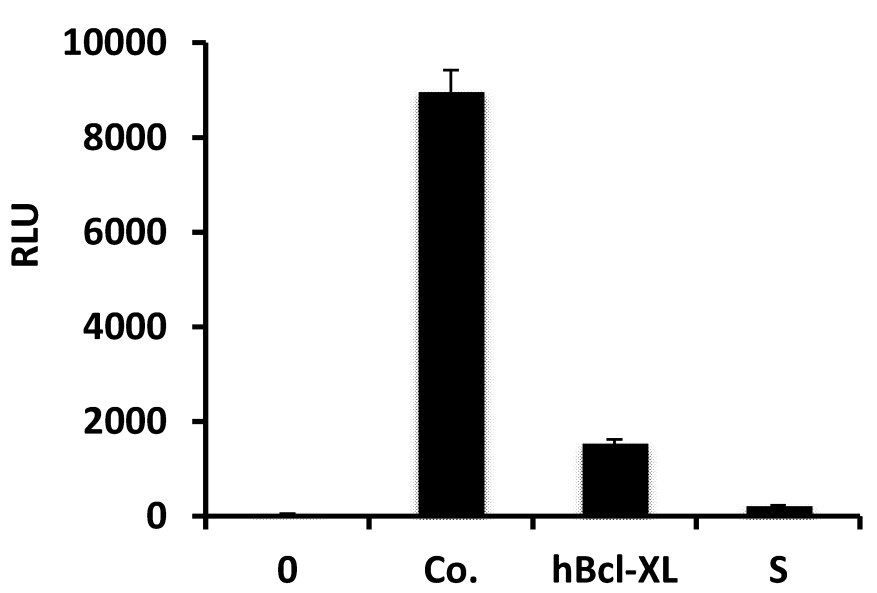

Supplementary Figure 6. VDAC and Bcl- $\mathbf{X}_{\mathrm{L}}$ are direct phosphorylation substrates for GSK3ß. Native purified mouse VDAC (mVDAC, A) human recombinant VDAC (hVDAC, B) and human recombinant Bcl- $\mathrm{X}_{\mathrm{L}}\left(\mathrm{hBcl}-\mathrm{X}_{\mathrm{L}}, \mathrm{C}\right)$ can be phosphorylated by GSK3 $\beta$ as shown by measurement of ATP content following incubation at $30^{\circ} \mathrm{C}$ for 30 min under stirring. Optimal doses are presented for each protein. 0 , Sample without ATP, Co., control sample containing the substrate protein (VDAC or Bcl- $\mathrm{X}_{\mathrm{L}}$ ), buffer and ATP but no kinase. S, synthetic substrate for hGSK3 $\beta$. RLU, relative unit measurement. The results are representative of three independent experiments. 